\title{
Muscle IL1 $\beta$ Drives Ischemic Myalgia via ASIC3-Mediated Sensory Neuron Sensitization
}

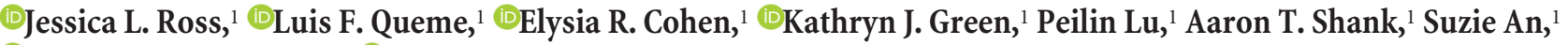 \\ ㅈenita C. Hudgins, ${ }^{1}$ and ${ }^{\circledR}$ Michael P. Jankowski ${ }^{1,2}$ \\ ${ }^{1}$ Department of Anesthesia, Division of Pain Management, Cincinnati Children's Hospital Medical Center, and 2Department of Pediatrics, University of \\ Cincinnati, Cincinnati, Ohio 45229
}

\begin{abstract}
Musculoskeletal pain is a significantly common clinical complaint. Although it is known that muscles are quite sensitive to alterations in blood flow/oxygenation and a number of muscle pain disorders are based in problems of peripheral perfusion, the mechanisms by which ischemic-like conditions generate myalgia remain unclear. We found, using a multidisciplinary experimental approach, that ischemia and reperfusion injury (I/R) in male Swiss Webster mice altered ongoing and evoked pain-related behaviors in addition to activity levels through enhanced muscle interleukin-1 beta (IL1 $\beta$ )/IL1 receptor signaling to group III/IV muscle afferents. Peripheral sensitization depended on acid-sensing ion channels (ASICs) because treatment of sensory afferents in vitro with IL1 $\beta$-upregulated ASIC3 in single cells, and nerve-specific knock-down of ASIC3 recapitulated the results of inhibiting the enhanced IL1 $\beta /$ IL1r1 signaling after I/R, which was also found to regulate afferent sensitization and pain-related behaviors. This suggests that targeting muscle IL1 $\beta$ signaling may be a potential analgesic therapy for ischemic myalgia.
\end{abstract}

Key words: ASICs; behavior; cytokines; electrophysiology; signaling; siRNAs

\section{Significance Statement}

Here, we have described a novel pathway whereby increased inflammation within the muscle tissue during ischemia/ reperfusion injury sensitizes group III and IV muscle afferents via upregulation of acid-sensing ion channel 3 (ASIC3), leading not only to alterations in mechanical and chemical responsiveness in individual afferents, but also to pain-related behavioral changes. Furthermore, these I/R-induced changes can be prevented using an afferent-specific siRNA knockdown strategy targeting either ASIC3 or the upstream mediator of its expression, interleukin 1 receptor 1 . Therefore, this knowledge may contribute to the development of alternative therapeutics for muscle pain and may be especially relevant to pain caused by issues of peripheral circulation, which is commonly observed in disorders such as complex regional pain syndrome, sickle cell anemia, or fibromyalgia.

\section{Introduction}

Musculoskeletal pain is one of the most common complaints of patients seeking medical treatment, but basic mechanisms of my-

Received Dec. 22, 2015; revised April 20, 2016; accepted May 11, 2016.

Author contributions: J.L.R. and M.P.J. designed research; J.L.R., L.F.Q., E.R.C., K.J.G., P.L., A.T.S., S.A., R.C.H., and M.P.J. performed research; J.L.R., L.F.Q., E.R.C., K.J.G., P.L., A.T.S., R.C.H., and M.P.J. analyzed data; J.L.R. and M.P.J. wrote the paper.

This work was supported by the National Institutes of Health-National Institute of Arthritis and Musculoskeletal and Skin Diseases (Grant R01AR064551-01A1), the Rita Allen Foundation and American Pain Society, the International Association for the Study of Pain Early Career Program, and the Department of Anesthesia at Cincinnati Children's Hospital Medical Center. We thank the Cincinnati Children's Hospital Medical Center Pathology Research Core for performing IL1 $\beta / \mathrm{H} \& \mathrm{E}$ costaining, Jordan Lamb for technical assistance, and Dr. Mark Baccei for helpful comments on this manuscript.

The authors declare no competing financial interests.

Correspondence should be addressed to Dr. Michael P. Jankowski, Department of Anesthesia, Division of Pain Management, Cincinnati Children's Hospital Medical Center, 3333 Burnet Avenue, MLC 6016, Cincinnati, OH 45229. E-mail: michael.jankowski@cchmc.org. algia development have yet to be determined fully (Mense, 2003, 2008). Although trauma and injury are major causes of muscle pain, another prominent cause of myalgia originates from complications in peripheral perfusion (Wasner et al., 2001; Coderre et al., 2004; Naves and McCleskey, 2005; Ali and Carman, 2012), which likely reflects the sensitivity of muscles to reduced oxygenation and blood flow (Blaisdell, 2002; Carmo-Araújo et al., 2007). Ischemic-like conditions are a known cause of muscle pain in numerous animal models and clinical conditions (Alam and Smirk, 1937; Sinoway et al., 1989; Coderre et al., 2004; Ross et al., 2014), including complex regional pain syndrome, sickle cell anemia, fibromyalgia, and peripheral vascular disorder (Wasner et al., 2001; Katz et al., 2007; Mense, 2008; Ali and Carman, 2012; Zempsky et al., 2013). These discrete conditions cause transient 
ischemic-like states that alter a number of inflammatory cytokines and growth factors designed to facilitate repair of the injured muscles (Carmo-Araújo et al., 2007; Eisenhardt et al., 2012; Ross et al., 2014). However, these same repair factors are also known to be algesic (Dina et al., 2008; Jankowski et al., 2009a; Jankowski and Koerber, 2010; Alvarez et al., 2014).

Recent testing of the response properties of individual group III and IV muscle afferents using our ex vivo forepaw muscles/ median and ulnar nerves/dorsal root ganglion (DRG)/spinal cord recording preparation in mice with ischemia and reperfusion (I/R) injury showed a significant decrease in mechanical thresholds and an increase in the number of muscle afferents responsive to both noxious ("high metabolite": $\mathrm{pH}$ 6.6, high lactic acid and ATP concentrations) and non-noxious ("low metabolite": $\mathrm{pH}$ 7.0, low lactic acid and ATP concentrations) mixtures of muscle metabolites (Sinoway et al., 1989; Light et al., 2008; Jankowski et al., 2013; Ross et al., 2014). Muscle afferent phenotypic switching may be a critical feature of I/R injury that leads to pain because these metabolite mixtures are known to be produced by the muscles during ischemic contractions (Li et al., 2008; Light et al., 2008; Birdsong et al., 2010) or during moderate exercise (Naves and McCleskey, 2005) and can produce sensations of "pain" or "fatigue" in humans, respectively (Pollak et al., 2014).

One possible candidate for pain generation after I/R injury is acid-sensing ion channel 3 (ASIC3), which has been associated with the generation of muscle pain in many animal models such as models of inflammation, incision, and cardiac ischemia (Immke and McCleskey, 2001a; 2001b; Sluka et al., 2003; Naves and McCleskey, 2005; Benson and McCleskey, 2007; Sluka et al., 2007). ASICs in group III/IV muscle afferents contribute to mechanosensation (Sluka et al., 2007; Walder et al., 2010) and afferent responsiveness to lactate and protons in the muscles (Immke and McCleskey, 2001a; 2001b; Naves and McCleskey, 2005; Light et al., 2008; Birdsong et al., 2010; Ross et al., 2014) and we have shown previously that cells responsive to both noxious and non-noxious metabolite mixtures after ischemia are more likely to express ASIC3 (Ross et al., 2014).

Of the cytokines and growth factors upregulated in I/Rinjured forepaw muscles, increased interleukin-1 beta (IL1 $\beta$ ) expression is of interest because its receptor, IL1r1 (Vigers et al., 1997), is also upregulated in the DRGs (Ross et al., 2014), suggesting a significant muscle-nerve interaction involving this pathway. Because injection of other inflammatory cytokines such as MCP-1 or IL- 6 into the muscles induces mechanical hypersensitivity (Dina et al., 2008; Alvarez et al., 2014), local cytokines likely influence muscle afferent sensitization after I/R, possibly through kinase-mediated signaling within the affected afferents (Hallegua and Weisman, 2002; O'Neill and Greene, 1998; Mense, 2003). Because of the specific increases in ASIC3 and IL1r1 in I/R-affected DRGs and upregulated IL1 $\beta$ in injured muscle tissue, we propose that enhanced muscle-expressed IL1 $\beta$ upregulates ASIC3 expression in muscle afferents during I/ $R$ via IL1r1 to induce peripheral sensitization, leading to the development of ischemic myalgia.

\section{Materials and Methods}

Animals. Male Swiss Webster mice ( $\sim 4-8$ weeks of age) were used for all analyses. Animals were housed in a climate-controlled, pathogen-free barrier facility with a $12 \mathrm{~h}: 12 \mathrm{~h}$ light/dark cycle at Cincinnati Children's Hospital Medical Center (CCHMC) under supervision of veterinary services and were given ad libitum access to standard rodent chow and water. All procedures were compliant with National Institutes of Health and AALAC International standards and were monitored and approved by the CCHMC Institutional Animal Care and Use Committee. Mice were anesthetized with $3 \%$ isofluorane for all surgical procedures. No analgesics were administered outside of the anesthesia used for surgeries during the study, which is in accordance with our approved animal protocols.

Ischemia/reperfusion surgery. For I/R injury, immediately after baseline (BL) behavior or $1 \mathrm{~d}$ before ex vivo analysis, the brachial artery of the right forelimb was exposed proximal to the ulnar artery/radial artery split and the brachial artery occluded by tying a 7-0 silk suture around the vessel and then closing the incision. Six hours after occlusion, the brachial artery suture was removed and the incision closed. Animals were allowed to recover in their home cages between surgeries. After the reperfusion surgery, I/R mice were allowed to recover for $18 \mathrm{~h}$ before $1 \mathrm{~d}$ behavioral or electrophysiological analysis or for up to $66 \mathrm{~h}$ for assays at the $3 \mathrm{~d}$ postocclusion time point. As described previously (Ross et al., 2014), specific assays also necessitated a sham surgical control wherein the suture was placed underneath the brachial artery, but not tied, during the initial surgery. As in our previous report, naive and sham mice were not found to be statistically different for any assay in this study and are thus combined for ease of presentation (see Table 2 and "Statistical analysis" section below).

siRNAs and nerve-specific injections. The specific targeting siRNAs used in these experiments were determined by first transfecting Neuro2A cells (ATCC) with one of four different ASIC3 or IL1r1 targeting duplexes (Thermo Scientific) and comparing the mRNA levels in these cultures with mRNA isolated from the nontargeting control siRNA-treated conditions. Real-time PCR analysis of cDNA (see below) generated from these various conditions confirmed the most efficiently targeting sequence for ASIC3 and IL1r1. The targeting sequence for our ASIC3 siRNAs used in the remaining studies presented here is as follows: $5^{\prime}$ UCC CUG ACU UCA AGA AUU AUU-3'. The sequence for the IL1r1 siRNAs was the following: 5'-UGA CUG GAC UGC UAG AGU AUU-3'. The nontargeting control sequence used here was obtained from Queme et al. (2016). This nontargeting sequence has been determined to not target any gene in the mouse genome (Thermo Scientific). These individual sequences were then modified with a $5^{\prime}$ thiol group on the sense strand (Thermo Scientific) to facilitate conjugation to the lipophilic peptide Penetratin-1 (MP Biomedicals), which has been shown to enhance neuronal transfection of conjugated cargos, including siRNAs, at $\sim 90-$ 95\% efficiency (Davidson et al., 2004; Jankowski et al., 2006). As the penetratin-linked siRNAs enters the reducing intracellular environment of a neuron, the disulfide linkage is broken, allowing the siRNAs to execute the degradation of their target mRNA effectively.

For siRNA injections, the median and ulnar nerves were exposed by slightly retracting the biceps muscles without damage to any vein or artery and lifted onto a Parafilm platform. Then, 0.1-0.2 $\mu \mathrm{l}$ of $90 \mu \mathrm{M}$ Penetratin-1 linked nontargeting control (PenCON), ASIC3-targeting (PenASIC3), or IL1r1-targeting (PenIL1r1) siRNAs were pressure injected directly under the epineurium of the median and ulnar nerves using a quartz microelectrode and picospritzer. These injections filled up $\sim 2 \mathrm{~mm}^{3}$ of space within the nerve, allowing the siRNAs to access the axons. After injection, Parafilm was removed and incision site closed. Before injection, siRNAs were warmed to $65^{\circ} \mathrm{C}$ for $5 \mathrm{~min}$.

The distance between the injection site and the DRGs was $\sim 20 \mathrm{~mm}$. siRNAs were injected $2 \mathrm{~d}$ before $\mathrm{I} / \mathrm{R}$ to allow for retrograde transport to the afferent cell bodies within the DRGs, similar to previous reports (Jankowski et al., 2009b, 2010, 2012a,b; Queme et al., 2016). This is the minimum amount of time needed to detect siRNAs in the DRGs after injection in vivo, which, based on the distance between injection site and DRG, is consistent with passive diffusion within axons and not active transport (Jankowski et al., 2009b, 2010). Furthermore, we also found that conjugating siRNAs to Penetratin-1 is necessary for knock-down because injecting unconjugated siRNAs into nerves of adult mice does not show any level of knock-down in vivo (data not shown). This siRNA injection paradigm has also been found not to induce antiviral-related responses (Jankowski et al., 2009b, 2010, 2012b) and thus allows the specific siRNAs to target the gene of interest for degradation in only the neurons with axons in the injected nerve without induction of antiviralrelated off-target effects. 
Nerve crush controls. An additional subset of mice was used to test for potential axonal injury during siRNA injections into the median and ulnar nerves. Animals given a PenCON siRNA injection as described above were compared with those with a nerve crush injury. For the nerve crush, the median and ulnar nerves of the right forelimb were exposed, each crushed with \#5 fine-tip forceps for 3-5 s, and visually inspected for the translucent appearance of the crush sites to confirm injury (Jankowski et al., 2009b; Ross et al., 2014). After transcardial perfusion with 3\% paraformaldehyde, the right C8 and T1 DRGs were excised and processed immunohistochemically as described below.

Protein isolation and Western blotting. The ipsilateral forepaw muscles from a single mouse or C7, C8, and T1 DRGs were excised from two mice and pooled for each condition ( $n=3$ per group) and then prepared for Western blot as described previously (Jankowski et al., 2009a,b, 2010, 2012a,b; 2014). Briefly, samples were homogenized in lysis buffer containing 1\% SDS, $10 \mathrm{~mm}$ Tris- $\mathrm{HCl}, \mathrm{pH} 7.4$, and protease inhibitors (1 $\mu \mathrm{g} / \mathrm{ml}$ pepstatin, $1 \mu \mathrm{g} / \mathrm{ml}$ leupeptin, $1 \mu \mathrm{g} / \mathrm{ml}$ aprotinin, $1 \mathrm{~mm}$ sodium orthovanadate, and $100 \mu \mathrm{g} / \mathrm{ml}$ phenylmethylsulfonyl fluoride; SigmaAldrich) and then $30 \mu \mathrm{g}$ of sample from each condition was centrifuged and boiled for $10 \mathrm{~min}$ in a denaturing buffer containing $\beta$-mercaptoethanol and SDS before gel electrophoresis. Using a $12 \%$ polyacrylamide SDS-PAGE gel, samples were then separated and transferred overnight to a PVDF (Millipore) membrane at $4^{\circ} \mathrm{C}$. Membranes were then blocked in LiCor Odyssey blocking buffer $(1: 1$ in $0.1 \mathrm{M} \mathrm{PB})$ and incubated in the following primary antibodies overnight at $4^{\circ} \mathrm{C}$ : IL1 $\beta$, 1:2000 (R\&D Systems); IL1r1, 1:1000, and ASIC3, 1:700 (both Millipore); and GAPDH, 1:2000 (ProSci). The LiCor Odyssey Imaging System and Image Studio version 3.1 software (LiCor) were used to detect secondary antibody (LiCor) binding of infrared-dye-conjugated donkey anti-guinea pig $(1: 10,000)$ or donkey anti-rabbit $(1: 20,000)$ at $800 \mathrm{~nm}$ and donkey anti-chicken at $680 \mathrm{~nm}(1: 20,000)$. Settings for detection were consistent between runs. Immunoreactive bands were analyzed by densitometry and quantified using ImageJ software. Optical density was normalized to GAPDH and reported as a fold change (mean \pm SEM).

Behavioral analyses. Assessments of spontaneous/ongoing pain-like behaviors (paw guarding), mechanical hypersensitivity (von Frey paw withdrawal thresholds), and muscle function (grip strength) were performed as described previously (Ross et al., 2014). Briefly, during morning light hours, mice were placed in a raised acrylic glass chamber with a steel mesh bottom and allowed to habituate for $30 \mathrm{~min}$ before testing. For guarding behaviors, mice were assigned a score of $0-2$ (where $0=$ mouse places foot firmly on mesh, 1 = mouse does not bear full weight on foot, and 2 mouse holds foot completely above mesh) every 5 min for $1 \mathrm{~h}$, totaling 12 observations. The average score for the 12 trials for each mouse per behavior day was used for analysis (Xu and Brennan, 2010). To assess mechanical hypersensitivity, the glabrous forepaw skin was stimulated using an increasing series of calibrated von Frey filaments $(0.07-4 \mathrm{~g})$. Threshold to withdrawal was recorded for three trials with 5 min intervals between each round and the average of the 3 trials was used for analysis. For grip strength testing, mice were held by the tail over a metal mesh grid connected to a grip strength meter (BioSeb) until they grasped the grid firmly with both forepaws only and then pulled back horizontally along the axis of the force sensor until they could not retain their grip. Neither hindpaw was allowed to come in contact with the grid. Grip strength was measured (in grams) in 3 rounds of 3 trials each, with $5 \mathrm{~min}$ between each round. These nine trials per mouse were averaged to assess mean grip strength on each behavioral day. BL measurements for each assessment were calculated immediately before I/R surgery and then at 1 and $3 \mathrm{~d}$ after injury.

This study also added voluntary wheel running to assess activity levels in our various conditions using an automated monitoring system (Lafayette Instruments) that measures numbers of revolutions, allowing for the calculation of velocity and distance traveled. After performing the other BL behaviors, but immediately before occlusion surgery, the mice were habituated to automated wheel cages (Lafayette Instruments) for 20-30 min. After the initial surgery, mice were singly housed in the wheel cages up to $3 \mathrm{~d}$ after I/R and removed solely for reperfusion surgery and/or other behavioral testing. Wheel-monitoring software recorded wheel ve- locity and distance traveled in hourly bins. Experimenters were blinded to animal injury conditions.

Ex vivo recording. We performed our single-unit muscle afferent electrophysiological recording analysis exactly as described previously (Jankowski et al., 2013; Ross et al., 2014; Queme et al., 2016). Briefly, mice were deeply anesthetized with $90 \mathrm{mg} / \mathrm{kg}$ ketamine and $10 \mathrm{mg} / \mathrm{kg}$ xylazine and perfused intracardially with ice-cold, oxygenated $\left(95 \% \mathrm{O}_{2} / 5 \% \mathrm{CO}_{2}\right)$ artificial CSF (aCSF) containing the following (in mM): $127.0 \mathrm{NaCl}, 1.9$ $\mathrm{KCl}, 1.2 \mathrm{KH}_{2} \mathrm{PO}_{4}, 1.3 \mathrm{MgSO}_{4}, 2.4 \mathrm{CaCl}_{2}, 26.0 \mathrm{NaHCO}_{3}$, and 10.0 $\mathrm{D}$-glucose. Then, the right forepaw muscles, median and ulnar nerves, C6-T2 DRGs, and spinal cord were dissected in continuity and transferred to a recording chamber filled with a separate solution of circulating, oxygenated aCSF that was kept on ice until recording. Once the preparation was positioned and ready for recording, the aCSF was slowly warmed to $32^{\circ} \mathrm{C}$. Quartz microelectrodes (impedance $>150 \Omega$ ) were used to intracellularly record from C7, C8, and T1 DRG sensory neuron somata. To isolate muscle afferents driven from the median and ulnar nerves alone, each nerve was gently pulled into a suction electrode that provided orthograde search stimuli $(0.4-2 \mathrm{~mA}, 1 \mathrm{~ms}$ duration at $0.5 \mathrm{~Hz})$. When an electrically active cell was found, a bipolar concentric electrode was used to localize its receptive field within the muscle $(6-8 \mathrm{~mA}, 1 \mathrm{~ms}$ duration). Once a forepaw muscle afferent was found, mechanical, thermal, and chemical stimuli were applied, with $\sim 20-30$ s of recovery time between each stimulus, to determine functional subtypes and response properties.

Mechanical responses were assayed using an increasing series of calibrated von Frey filaments $(0.07-8 \mathrm{~g})$. Thermal responses were tested using $\sim 1 \mathrm{ml}$ of cold, then hot, physiological saline $\left(\sim 1^{\circ} \mathrm{C}\right.$ and $52^{\circ} \mathrm{C}$, respectively) gently applied directly to the receptive field at a variable flow rate. Last, chemosensitivity was determined via application of $10 \mathrm{ml}$ of oxygenated "low" (15 mm lactate, $1 \mu \mathrm{M}$ ATP, pH 7.0) and then "high" (50 mM lactate, $5 \mu \mathrm{M}$ ATP, pH 6.6) metabolite solutions (in warmed $\mathrm{aCSF}$ ) delivered to the inner recording chamber containing the muscles using a valve controller with an inline heater. Because of its rapid degradation, ATP was added to the metabolite solutions just before their application. After metabolites were applied, the mechanical and thermal stimuli were repeated to determine any effects of chemical stimulation on mechanical or thermal responses in individual cells. As in our previous studies (Jankowski et al., 2013; Ross et al., 2014), no sensitization to mechanical or thermal stimuli was detected as a result of chemical stimulation, nor were there any differences in firing or response types for any stimulus measured between cells recorded at the beginning of an experiment and those recorded at the end of an experiment in a given condition (data not shown). Therefore, it is highly unlikely that we were experiencing any thermal or chemical sensitization in our recording preparations. Conduction velocities (CVs) were calculated using the distance between the DRG and the suction electrode along with the recorded spike latency observed after electrical stimulation. Sensory neurons were originally divided into group III and IV types based upon their response characteristics, CVs, and spike shapes (Jankowski et al., 2013). Parameters that were characterized offline using Spike2 software included subtype prevalence, mechanical thresholds, thermal (hot/cold), and chemical ("low" and "high" metabolite mixtures) responsiveness and mean peak instantaneous frequencies (IFs) to each stimulus type.

A total of 318 cells were recorded and characterized from the various conditions (naive: 45, control I/R: 96, PenIL1r1 + I/R: 67, PenASIC3 + I/R: 68, 3 d I/R: 42). Group III and IV afferents were not found to be significantly different in any of our experimental groups and thus were combined for analysis. A subset of functionally characterized cells were iontophoretically injected with 5\% neurobiotin (NB; Vector Laboratories) to be analyzed via immunohistochemistry using standard processing methodologies (see below) or filled with Lucifer yellow (Sigma-Aldrich) for single-cell qPCR, allowing for the assessment of the neurochemical or molecular identity of single functionally defined muscle afferents, respectively. A total of 37 cells underwent neurochemical analysis. These same sections were also used to quantify DRG cell numbers (see below) in all injury conditions $(n=3-7)$. For single-cell qPCR $(n=6)$, DRGs with labeled cells were collected, cultured in vitro using 
standard dissociation protocols (Jankowski et al., 2006; Malin et al., 2007; below), and processed for single cell real-time PCR (below).

Immunohistochemistry. Immunohistochemistry was performed as described previously (Jankowski et al., 2013; Ross et al., 2014; Queme et al., 2016). C7, C8, or T1 DRGs containing NB-labeled cells were excised and postfixed in $3 \%$ paraformaldehyde for $30 \mathrm{~min}$ and then embedded in $10 \%$ gelatin, incubated overnight in $3 \%$ paraformaldehyde, and cryoprotected in $20 \%$ sucrose. Embedded DRG sections $(45 \mu \mathrm{m})$ were first treated with $10 \mathrm{~mm}$ citrate buffer, $\mathrm{pH} 6.0$, at $72^{\circ} \mathrm{C}$ for antigen retrieval, then blocked in Tris-buffered saline containing bovine serum albumin and Triton X-100 (10\% and 0.1\%, respectively; Sigma-Aldrich) and incubated overnight with primary antibodies for acid-sensing ion channel 3 (guinea pig anti-ASIC3, 1:2000; Millipore) and P2X3 (rabbit antiP2X3, 1:2000; Thermo Scientific), phosphorylated c-Jun-N-terminal kinase (rabbit anti-pJNK, 1:100; Cell Signaling Technology), activated extracellular signal related kinase 1/2 (rabbit anti-pERK1/2, 1:200; Cell Signaling Technology), phosphorylated p38 MAP kinase (rabbit anti-pp38, 1:200; Cell Signaling Technology), activated Src kinase (rabbit antipSrc, 1:200; Cell Signaling Technology) and/or P2X3 (rabbit anti-P2X3, 1:2000; Thermo Scientific). Sections were then labeled fluorescently with corresponding secondary antibodies (anti-guinea pig Alexa Fluor 647, 1:400, or anti-rabbit Alexa Fluor594, 1:400; both Jackson Immuno Research), as well as FITC-Avidin (1:750; Vector Laboratories) for visualization of NB. For comparison of PenCON injection and nerve crush, DRGs were processed using rabbit anti-ATF3 (1:1000; Millipore) primary antibody and anti-rabbit Alexa Fluor 594. All sections were mounted on gelatin-coated permafrost slides with Fluoro-Gel (Electron Microscopy Sciences) and stored in the dark at room temperature. A separate set of DRGs from naive mice was used to confirm cellular presence of IL1r1 and were processed with rabbit anti-IL1r1 (1:250; AbCam) and mounted with Fluoro-Gel II containing 4',6-diamidino-2phenylindole (Electron Microscopy Sciences).

For analysis of IL1 $\beta$ localization within forepaw muscle tissue, agematched naive and $1 \mathrm{~d}$ I/R mice were perfused with $3 \%$ paraformaldehyde. Before excision of the right forepaw, all overlying skin was removed. Before paraffin embedding, tissue was decalcified to soften bones for sectioning at $5 \mu \mathrm{m}$. All staining of muscle tissue was performed using the Discovery XT (Ventana) automated staining platform. After pretreatment with citrate (Ventana $\mathrm{CC} 2$ reagent), $\mathrm{pH} 6.0$, at $72^{\circ} \mathrm{C}$, slides were incubated with rabbit anti-IL1 $\beta$ ( $1: 75$; Abcam) for $32 \mathrm{~min}$ and then labeled using an UltraMap diaminobenzidine (DAB) Detection Kit (Ventana) for detection of HRP-conjugated anti-rabbit secondary antibody binding. After DAB processing, slides were counterstained with H\&E (Ventana Bluing Reagent) or hematoxylin only for 4 min each, dehydrated in a graded ethanol and xylene series, and coverslipped in xylene-based mounting medium. Paraffin embedding, sectioning, and immunohistochemical processing were performed by the CCHMC Pathology Research Core. All labeling was characterized and documented using Leica inverted fluorescence/bright-field or confocal microscopes with sequential scanning to avoid bleed-through of the different fluorophores. Images were compiled and prepared for publication using Photoshop (Adobe).

Cell counting. For average cell numbers, DRGs processed for single-cell immunohistochemistry as described above were used. Methods for obtaining average cell numbers were performed here according to a slightly modified version of previous procedures (Christianson et al., 2006; Jankowski et al., 2009a). On each slide that had been stained for ASIC3 and P2X3, three random, nonoverlapping sections not containing a NBlabeled afferent were scanned using the Leica confocal microscope to create a $Z$-stack of the full DRG section at $3 \mu \mathrm{m}$ intervals. Then, $20 \mu \mathrm{m}$ optical sections were used for analysis to estimate total cell numbers. ASIC3-positive and P2X3-positive cells were counted in the optical sections using Neurolucida software to ensure that cells were not counted twice. Both markers were quantified in the same sections per slide. Total cells per section were determined for each marker and averaged among the three random sections per slide. Counts were performed on three to seven slides per condition, with each slide corresponding to a representative DRG from a single animal, and the average counts per condition were used for analysis. Separate sections that were stained for p-JNK and ASIC3 were also quantified in the above manner $(n=3-4)$.

Fluorogold tracer injection. For specific molecular analysis of forelimb afferents, $10 \mu \mathrm{l}$ of $4 \%$ Fluorogold (FG; Fluorochrome) was injected into the right forepaw muscles using a $1 \mathrm{cc}$ syringe with a 30 gauge needle (Molliver et al., 2005). A 10-14 d incubation period was used to ensure retrograde transport of the tracer to the DRGs. After removal of DRGs, cells were cultured according to the procedures described below.

Cell culture. For primary DRG neuron cultures (Jankowski et al., 2006; Malin et al., 2007), appropriate DRGs of FG-injected mice or DRGs obtained from ex vivo recording were collected in HBSS, dissociated with cysteine/papain (0.03\%, Sigma-Aldrich, and $20 \mathrm{U} / \mathrm{ml}$, Worthington), followed by collagenase II ( $0.3 \%$; Worthington), and then triturated in F12 complete medium (F12 containing 10\% fetal bovine serum and 1\% penicillin/streptomycin) before plating onto poly-D-lysine/laminin (20 $\mu \mathrm{g} / \mathrm{ml}$ each; Sigma-Aldrich)-coated glass coverslips placed in $35 \mathrm{~mm}$ Petri dishes. Cells were allowed to incubate for $1-2 \mathrm{~h}$ and then flooded with $1 \mathrm{ml}$ of F12 complete medium or F12 containing $50 \mathrm{ng} / \mathrm{ml} \mathrm{IL1} \beta$ (R\&D Systems), $50 \mathrm{ng} / \mathrm{ml}$ IL1 $\beta$ plus $10 \mu \mathrm{M}$ SP600125 (JNK inhibitor II; Millipore), $10 \mu \mathrm{M}$ SP600125 alone, $2.5 \mu \mathrm{g}$ of CAPE alone (NF $\kappa \mathrm{B}$ inhibitor; Calbiochem), or $50 \mathrm{ng} / \mathrm{ml} \mathrm{IL1} \beta$ plus $2.5 \mu \mathrm{g}$ of CAPE overnight for subsequent single-cell analysis and/or immunohistochemistry. For cells obtained from ex vivo recording, cells were allowed to incubate for up to $1 \mathrm{~h}$. At the designated time, cells were then flooded with single-cell PCR buffer containing the following (in $\mathrm{mM}$ ): $140 \mathrm{NaCl}, 10$ glucose, $5 \mathrm{KCl}, 10$ HEPES, $1 \mathrm{MgCl}_{2}$, and $2 \mathrm{CaCl}_{2}$. Individual cells were collected using borosilicate electrodes and the Cell Tram Vario system (Eppendorf) under bright-field optics after fluorescence detection using a Leica inverted microscope.

Single-cell cDNA amplification and real-time PCR. All collected single cells were used in real-time PCRs based on a modified protocol from Kurimoto et al. (2007) as follows: collected cells were lysed in buffer containing 4\% IGEPAL, dNTPs, Oligo dT, and prokaryotic spike RNAs (1000 copies of LYS transcripts) used for internal and reverse transcription quality controls because internal controls such as GAPDH will invariably differ from cell to cell. RNAs were reverse transcribed with Superscript III (Invitrogen) for $5 \mathrm{~min}$ to minimize the length of cDNAs being produced and to reduce bias from other cDNA amplification methods using Oligo dT primers (Kurimoto et al., 2006; Kurimoto et al., 2007). The unreacted first-strand primer was excised with exonuclease I and a poly-A tail was added to single cDNA strands. A second strand was then synthesized and cDNAs were amplified globally using ExTaq (Takara) polymerase in a 20-cycle PCR. cDNA samples were diluted at 1:20 (1:10 for LYS) and used in SYBR Green qPCRs according to our previously described procedures (Jankowski et al., 2014; Ross et al., 2014; see below). To verify that our spike RNA strategy was sufficient, we also diluted whole DRG RNA to different single-cell levels (5, 10, and $100 \mathrm{pg}$ ) and performed real-time PCR using these methods to confirm that, even under conditions of differing total starting RNA concentrations, we could obtain a consistent expression of our spike RNA (LYS; see Fig. 3c).

For real-time PCR analysis, diluted cDNAs were run in duplicate SYBR Green real-time PCRs (20 ng/reaction) on a Step-One real-time PCR machine (Applied Biosystems). The forward and reverse primer sequences used for analysis have been described previously (Ross et al., 2014) except for LYS (see below), ASIC2, and GAPDH. The primer sequences used for ASIC2 are as follows: forward: 5' -GCA CCT GTG GAG GAA GTA CG-3'; reverse: 5' -CCC GCC CCA AAC AAA AAT CAG-3'. For GAPDH, the following shortened sequence was used: forward: $5^{\prime}$ ATG TGT CCG TCG TGG ATC TGA-3'; reverse: 5' -ATG CCT GCT TCA CCA CCT TCT T-3'. GAPDH was first tested in each sample to verify acquisition of single cell cDNAs. Cycle time $(\mathrm{Ct})$ values for all targets were normalized to the LYS spike RNA control (forward: 5' -GCC ATA TCG GCT CGC AAA TC-3'; reverse: 5'-AAC GAA TGC CGA AAC CTC CTC- $3^{\prime}$ ) for single-cell qPCR. $\Delta \Delta$ Ct values (used to determine fold change) were then obtained by subtracting the normalized target gene's $\mathrm{Ct}$ value from naive/untreated controls. Then fold change was calculated as $2^{\Delta \Delta \mathrm{Ct}}$ (Applied Biosystems) and reported as mean \pm SEM.

Statistical analysis. The fold change in protein expression detected in Western blot and in single-cell mRNA expression were analyzed via one- 
a

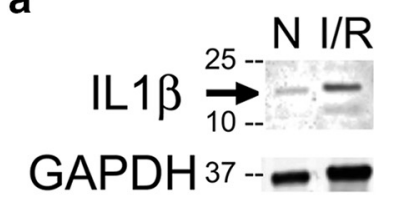

d

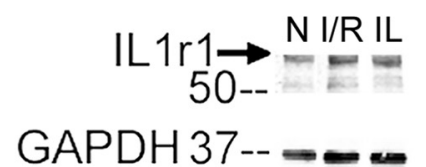

GAPDH $37---\cdots$

g

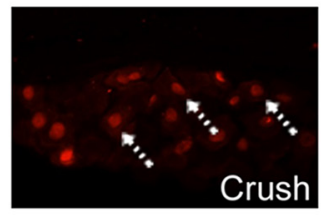

b

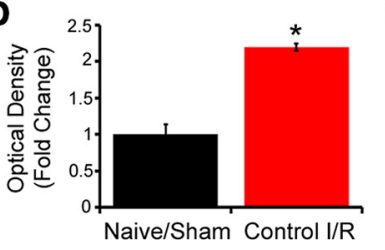

e ${ }^{2.5}+\quad$ f
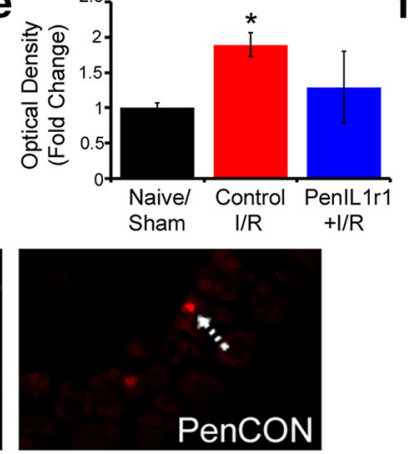

h
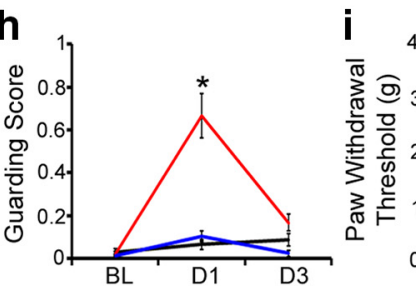

4
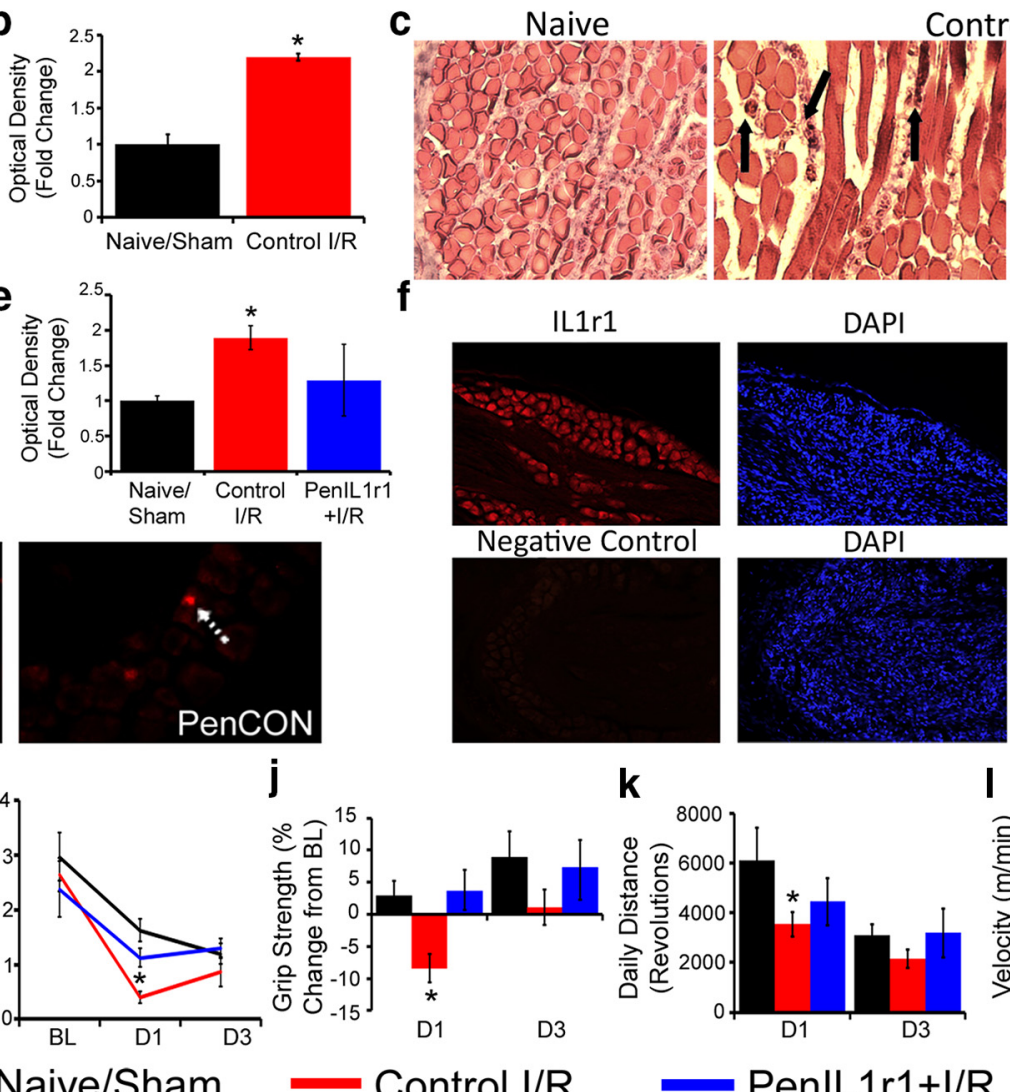

k
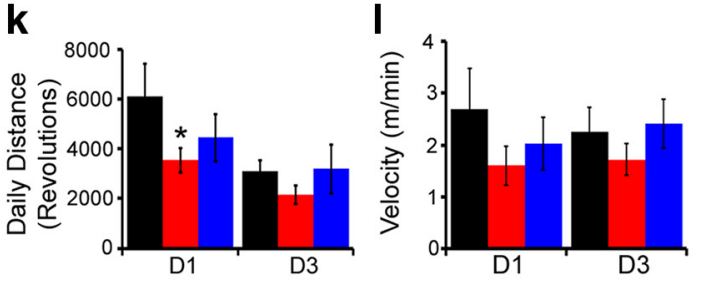

Figure 1. Increased IL1 $\beta$ signaling at the IL $1 \mathrm{r} 1$ receptor regulates myalgia-related behaviors after I/R injury. Increased muscle IL1 $\beta$ protein expression $1 \mathrm{~d}$ after I/R ( $\boldsymbol{a}, \boldsymbol{b}$ ) is localized to macrophages and neutrophils (arrows) present in injured muscles (c) as visualized with hematoxylin and eosin stain (left) or IL1 $\beta$ with hematoxylin only (right). $n=2$. Expression of IL1r1 also increases in the affected DRGs $(\boldsymbol{d}, \boldsymbol{e})$, but nerve-specific siRNA knock-down of IL1r1 (PenIL1r1 $+\mathrm{I} / \mathrm{R}$ ) prevents this I/R-induced upregulation ( $n=3$ ). Knock-down of the receptor likely affected all neuronal cell types because IL1r1 was immunocytochemically localized $(n=3)$ to most DRG neurons $(\boldsymbol{f})$. $g$, ATF3 (red) was used to mark injured neurons (arrows) in the affected C 8 or T1 DRGs $1 \mathrm{~d}$ after either a median and ulnar nerve crush or an injection of nontargeting, control siRNAs (PenCON) into the median and ulnar nerves ( $n=2-3$ per condition). Crush injury readily induces ATF3 expression in DRGs, whereas PenCON injection does not. Behavioral deficits caused by I/R are also attenuated with IL1r1 knock-down ( $n \geq 8$ per injury condition per task). $\boldsymbol{h}$, Spontaneous paw-guarding behaviors increase significantly $1 \mathrm{~d}$ after injury in the control I/R group compared with PenIL1 $1+\mathrm{I} /$ R and naive/sham animals. Furthermore, control I/R animals showed a significant improvement within their group on D3 compared with D1 function $(p<0.001)$, whereas the other groups showed no significant guarding behaviors over time ( $p \geq 0.101)$. Both paw withdrawal threshold (i) and grip strength ( $\boldsymbol{j}$ ) decreased significantly $1 \mathrm{~d}$ after I/R, but these effects were attenuated by IL $1 \mathrm{r} 1 \mathrm{knock}$-down. $0 \mathrm{n}$ D3, the effects of I/R alone had resolved in both tests. $\boldsymbol{k}$, Voluntary activity is significantly decreased within $1 \mathrm{~d}$ after $\mathrm{I} / \mathrm{R}$, but is no different from PenIL $1 \mathrm{r} 1+\mathrm{I} / \mathrm{R}$ or naive/sham animals by D3. Average velocity is also not different between groups on any testing day (I). Data are represented as mean \pm SEM and were analyzed via one-way ANOVA with Tukey's post hoc or two-way RM ANOVA with Holm-Sidak post hoc tests. * $p<0.05$ compared with naive/sham.

way ANOVA with Tukey's or Holm-Sidak post hoc tests. An additional post hoc false discovery rate correction was used to validate single-cell mRNA statistical analyses. Behavioral data were first analyzed with oneor two-way repeated measures (RM) ANOVAs with Holm-Sidak post hoc test on all tested conditions to ensure that there were no between-group differences in the naive/sham and control I/R conditions and to validate our statistical analyses before collapsing for presentation. Differences in phenotype frequency between groups were compared with either $\chi^{2}$ analysis (with Yates correction when applicable) or Fisher's exact test. Firing frequencies and thresholds to different stimuli were compared via Kruskal-Wallis one-way ANOVA on ranks with Dunn's post hoc test and cell counts were analyzed using one-way ANOVA with Tukey's post hoc test. For all statistical procedures, the critical significance level was defined at $p<0.05$.

\section{Results}

Inhibition of IL1r1 in muscle afferents blocks pain-related behaviors induced by ischemia and reperfusion injury To confirm the findings from our previous study analyzing mRNA levels in the muscles and DRGs (Ross et al., 2014), we first quantified the relative protein expression of IL $1 \beta$ and IL $1 \mathrm{r} 1$ in the forepaw muscles and C7/C8/T1 DRGs, respectively, $1 \mathrm{~d}$ after I/R.
We confirmed that, compared with naive/sham animals (sham vs naive: $1.04 \pm 0.24$-fold, $p>0.05$ ), IL1 $\beta$ protein is significantly upregulated in the muscles after I/R (Fig. $1 a, b$; control I/R: $2.2 \pm$ 0.05 -fold increase vs naive/sham, $p<0.05$; one-way ANOVA with Tukey's) and this appeared to be expressed in neutrophils and macrophages (Fig. 1c). We also verified the upregulation of IL1r1 at the protein level in the DRGs (Fig. $1 d, e$; control I/R: $1.89 \pm 0.16$-fold increase; PenCON $+\mathrm{I} / \mathrm{R}: 1.85 \pm 0.19$-fold increase; I/R alone: $1.94 \pm 0.32$-fold increase; $p>0.05$ vs each other, see below; vs naive/sham, $p=0.014$, sham vs naive: $0.98 \pm$ $0.09, p>0.05$, one-way ANOVA with Tukey's test). Using immunocytochemistry, we determined that IL1r1 appeared to be localized to all neurons in the DRG (Fig. 1f). Therefore, we wanted to test the hypothesis that upregulation of IL1r1 specifically in sensory neurons after I/R was responsible for our previously observed alterations in pain-related behaviors and muscle afferent sensitization (Ross et al., 2014).

Therefore, we used a novel nerve-specific siRNA knock-down strategy (Jankowski et al., 2009b, 2010, 2012a,b) to ensure that we could effectively prevent the dynamic upregulation of IL1r1 after 
Table 1. Behavioral analyses and electrophysiological recording measurements during ex vivo recording in mice with $\mathrm{I} / \mathrm{R}$ alone or PenCON $+\mathrm{I} / \mathrm{R}$

\begin{tabular}{|c|c|c|c|c|c|c|}
\hline & \multicolumn{6}{|c|}{ Behavioral assessments } \\
\hline & \multicolumn{3}{|c|}{ Mean guarding score } & \multicolumn{3}{|c|}{ Mean paw withdrawal threshold } \\
\hline & $\mathrm{BL}$ & D1 & D3 & $\mathrm{BL}$ & D1 & D3 \\
\hline I/Ralone & $0.024 \pm 0.02$ & $0.79 \pm 0.15$ & $0.2 \pm 0.06$ & $3.18 \pm 0.44$ & $0.27 \pm 0.77$ & $1.07 \pm 0.53$ \\
\hline \multirow[t]{3}{*}{ PenCON $+\mathrm{I} / \mathrm{R}$} & $0.021 \pm 0.01$ & $0.56 \pm 0.15$ & $0.13 \pm 0.05$ & $2.15 \pm 0.38$ & $0.53 \pm 0.19$ & $0.67 \pm 0.13$ \\
\hline & \multicolumn{2}{|c|}{ Mean daily wheel distance } & \multicolumn{2}{|c|}{ Mean wheel velocity } & \multicolumn{2}{|c|}{$\%$ change grip strength } \\
\hline & D1 & D3 & D1 & D3 & D1 & D3 \\
\hline I/R alone & $3446.4 \pm 673$ & $3929.2 \pm 824$ & $1.45 \pm 0.34$ & $1.71 \pm 0.35$ & $-12.37 \pm 6.2$ & $-1.73 \pm 5.6$ \\
\hline \multirow[t]{4}{*}{ PenCON $+\mathrm{I} / \mathrm{R}$} & $3104.9 \pm 613$ & $2994.6 \pm 403$ & $1.74 \pm 0.66$ & $1.73 \pm 0.36$ & $-9.98 \pm 4.5$ & $0.11 \pm 5.48$ \\
\hline & \multicolumn{6}{|c|}{ Ex vivo measurements } \\
\hline & \multicolumn{3}{|l|}{ Response counts } & \multicolumn{3}{|c|}{ Mechanical thresholds } \\
\hline & Low met & High/both & All met & Mean & SEM & $n$ \\
\hline I/R alone & $1 / 25$ & $6 / 46$ & $7 / 71$ & 1.45 & 0.76 & 10 \\
\hline PenCON + I/R & $2 / 28$ & $11 / 49$ & $13 / 77$ & 1.19 & 0.52 & 7 \\
\hline
\end{tabular}

Values are presented as means \pm SEM.

Table 2. Behavioral analyses in naive mice compared with those that had sham surgery

\begin{tabular}{|c|c|c|c|c|c|c|}
\hline & \multicolumn{6}{|c|}{ Behavioral assessments } \\
\hline & \multicolumn{3}{|c|}{ Mean guarding score } & \multicolumn{3}{|c|}{ Mean paw withdrawal threshold } \\
\hline & $\mathrm{BL}$ & D1 & D3 & $B L$ & D1 & D3 \\
\hline Naive & $0.028 \pm 0.03$ & $0.056 \pm 0.06$ & $0.056 \pm 0.06$ & $2.78 \pm 0.62$ & $2.02 \pm 0.22$ & $0.78 \pm 0.35$ \\
\hline \multirow[t]{3}{*}{ Sham } & $0.042 \pm 0.03$ & $0.063 \pm 0.03$ & $0.114 \pm 0.04$ & $2.31 \pm 0.55$ & $1.19 \pm 0.19$ & $1.32 \pm 0.32$ \\
\hline & \multicolumn{2}{|c|}{ Mean daily wheel distance } & \multicolumn{2}{|c|}{ Mean wheel velocity } & \multicolumn{2}{|c|}{$\%$ change grip strength } \\
\hline & D1 & D3 & D1 & D3 & D1 & D3 \\
\hline Naive & $4061.7 \pm 1375$ & $2454.7 \pm 874$ & $2.84 \pm 1.15$ & $1.95 \pm 0.69$ & $0.073 \pm 2.4$ & $10.8 \pm 6.4$ \\
\hline Sham & $5324.9 \pm 1342$ & $2883.8 \pm 478$ & $1.88 \pm 0.77$ & $2.15 \pm 0.38$ & $5.01 \pm 3.6$ & $9.07 \pm 5.79$ \\
\hline
\end{tabular}

Values are presented as means \pm SEM.

$\mathrm{I} / \mathrm{R}$ at the protein level in the injured afferents. To control for injection-related effects, we used a control, nontargeting siRNA in conjunction with our injury model (PenCON $+\mathrm{I} / \mathrm{R})$. We first assessed expression of activating transcription factor 3 (ATF3), a marker of neuronal injury (Tsujino et al., 2000), in the DRGs, finding that, similar to previous reports (Jankowski et al., 2009b), our siRNA injection paradigm did not cause any significant damage to the muscle afferents to be studied (Fig. $1 g$ ). Furthermore, the injection of these nontargeting siRNAs in mice with I/R injury did not alter any measure tested in this study compared with mice with I/R alone (Table 1); therefore, data from these two conditions were combined for ease of presentation. Similar results were found between naive and sham groups (Table 2) and were therefore also combined for ease of presentation and to enhance statistical power. Compared with naive/sham animals, the upregulation of IL1r1 protein in the C7/C8/T1 DRGs of control $\mathrm{I} / \mathrm{R}$ mice $(1.89 \pm 0.16)$ was prevented by injection of IL1r1targeting siRNAs (PenIL1r1 + I/R) into the median and ulnar nerves in mice with $\mathrm{I} / \mathrm{R}$ (Fig. $1 d$,e; $1.29 \pm 0.51$-fold increase vs naive/sham, $p>0.05, p=0.049$ vs I/R). Because we determined that IL1r1 appeared to be localized to all neurons in the DRG (Fig. $1 f$ ), this knock-down was likely to affect all cell types undergoing dynamic expression changes after I/R.

To assess the effects of nerve-specific IL1r1 knock-down on pain-related behaviors known to occur after I/R (Ross et al., 2014), we used multiple interrelated behavioral assays to measure spontaneous and evoked pain, as well as muscle strength and voluntary activity. First, we analyzed paw-guarding behaviors to assess spontaneous/ongoing pain-related behaviors (Fig. 1h). On the first postinjury day (D1), the control I/R animals $(n=15)$ showed significantly more paw-guarding behaviors $(0.67 \pm 0.11)$ than at $\mathrm{BL}(0.02 \pm 0.01, p<0.001)$ and compared with D1 scores of both naive/sham $(0.1 \pm 0.02, p<0.001 ; n=14)$ and PenIL1r1 $+\mathrm{I} / \mathrm{R}(0.10 \pm 0.03, p<0.001 ; n=8)$ mice. Effects of I/R on ongoing pain-related behaviors were found to be resolved by D3 (naive/sham: $0.1 \pm 0.03$, control I/R: $0.17 \pm 0.04$, PenIL1r1 + I/R: $0.02 \pm 0.02, p \geq 0.398$; two-way RM ANOVA with HolmSidak test). The naive/sham and PenIL1r1 + I/R animals did not differ in average guarding score $(p=0.615)$ at any time point.

We assessed mechanical hypersensitivity (Fig. 1i) using an increasing series of calibrated von Frey filaments to stimulate the plantar surface of the forepaws (Ross et al., 2014). At the D1 time point, we found a significant effect of I/R in decreasing paw withdrawal threshold $(0.41 \pm 0.11 \mathrm{~g})$ compared with their BL $(2.64 \pm$ $0.31 \mathrm{~g})$ or to time-matched naive/sham $(1.5 \pm 0.17 \mathrm{~g})$ animals $(p=0.005)$. This difference was resolved by D3 $(0.87 \pm 0.27 \mathrm{~g}$; $p \geq 0.799)$. All groups showed a slight decrease in threshold over time $(p \leq 0.05)$; however, the PenIL1r1 + I/R and naive/sham conditions did not differ from each other at any time point (naive/sham: $\mathrm{BL}=2.6 \pm 0.43 \mathrm{~g}, \mathrm{D} 1=1.5 \pm 0.17 \mathrm{~g}, \mathrm{D} 3=1.2 \pm$ $0.22 \mathrm{~g} ;$ PenIL1r1 + I/R: $\mathrm{BL}=2.38 \pm 0.5 \mathrm{~g}, \mathrm{D} 1=1.12 \pm 0.17 \mathrm{~g}$, $\mathrm{D} 3=1.3 \pm 0.19 \mathrm{~g} ; p \geq 0.266$; two-way RM ANOVA with Holm-Sidak test).

We also assessed muscle function among our groups by measuring forelimb grip strength (Fig. 1j). Control I/R animals showed significant grip strength impairment compared with both PenIL1r1 + I/R and naive/sham animals (naive/sham: $2.87 \pm 2.38 \%$, control I/R: $-8.45 \pm 2.21 \% ; p=0.003$; PenIL1r1 

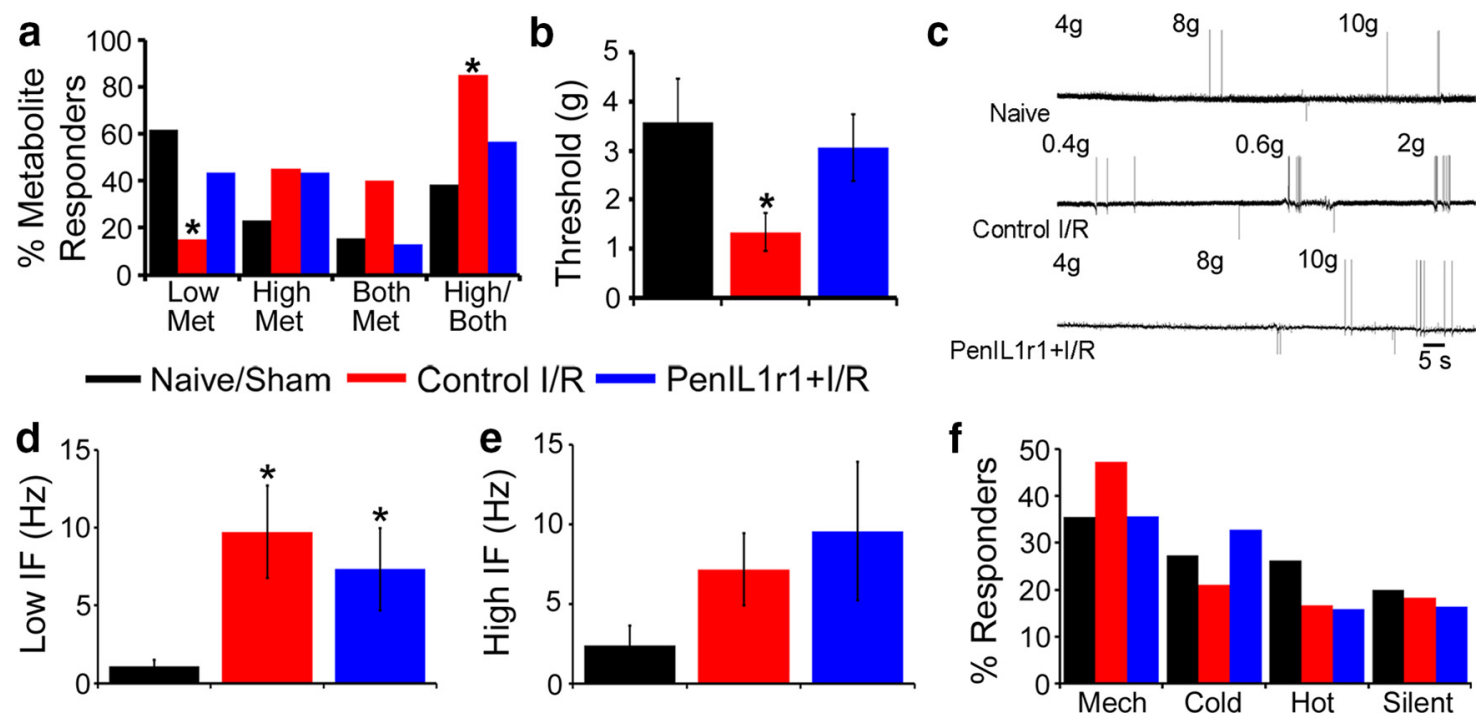

Figure 2. Nerve-specific siRNA knock-down of IL1r1 alters I/R-induced changes in group III and IV muscle afferent phenotypes and response properties as assessed by ex vivo recording. $\boldsymbol{a}$ Compared with naive muscle afferents, $I / R$ decreases the total number of cells responding to low (innocuous) metabolite solutions and increases the number of cells responsive to either high (noxious) metabolites or both of these solutions; however, afferent phenotypes recorded in the PenlL1r $1+\mathrm{I} / \mathrm{R}$ condition were no different from naïve. ${ }^{*} p<0.05, \chi^{2}$ analysis. $n \geq 45$ characterized cells per condition. $\boldsymbol{b}, \mathrm{LL} 1 \mathrm{r} 1 \mathrm{knock}$-down also prevents the I/R-associated decrease in mechanical threshold. $\boldsymbol{c}$, Examples of responses to mechanical deformation of the muscles in naive/sham, control $\mathrm{I} / \mathrm{R}$, and PenIL $1 \mathrm{r} 1+\mathrm{I} / \mathrm{R}$ mice. $\boldsymbol{d}$, Although I/R caused increased firing to low metabolites, nerve-specific inhibition of IL $1 \mathrm{r} 1$ did not restore mean peak instantaneous firing frequencies to this metabolite solution back to naive levels. $\boldsymbol{e}$, Instantaneous frequencies to high metabolites were also not different in any group. $\boldsymbol{f}, \mathrm{I} / \mathrm{R}$ did not alter total numbers of thermally sensitive, mechanically responsive, or silent fibers and siRNA knock-down of IL $1 \mathrm{r} 1$ also did not affect these phenotypes. Data are represented as mean \pm SEM and were analyzed via Kruskal-Wallis one-way ANOVA on ranks with Dunn's test. ${ }^{*} p<0.05$ compared with naive.

$+\mathrm{I} / \mathrm{R}: 3.59 \pm 3.37 \% ; p=0.015$ vs $\mathrm{BL})$ at the $\mathrm{D} 1$ time point; however, the naive/sham and PenIL1r1 $+\mathrm{I} / \mathrm{R}$ groups did not differ $(p=0.896)$. Functional recovery was detected by D3 in the control I/R group $(1.08 \pm 2.75 \%, p>0.05$ vs D1 and D3 naive/ sham and PenIL1r1 + I/R). Data from these new cohorts of naive/sham and control I/R animals completely confirmed our recent report in mice with I/R (Ross et al., 2014).

Finally, we also measured voluntary running activity in each animal using an automated wheel-monitoring system (Fig. $1 k, l$ ). Although control I/R animals ran significantly fewer revolutions than naive/sham animals on D1 (control I/R: $3546 \pm 491$ revolutions, naive/sham: $6124 \pm 1279$ revolutions; $p=0.036$ ), PenIL1r1 + I/R animals did not differ from either group in distance traveled (4453 \pm 938 revolutions, $p \geq 0.09$ ); however, by D3, all experimental groups showed similar distances traveled (naive/sham: $3100 \pm 429$ revolutions, control I/R: $2156 \pm 374$ revolutions, PenIL1r1 + I/R: $3188 \pm 992$ revolutions; $p \geq 0.27$ ). No significant differences in running speed were found between these three treatment groups $(p \geq 0.39$ ). The restoration of all behavioral effects of I/R back to naive levels at the $\mathrm{D} 3$ time point also supports the notion that our knock-down of IL1r1 is likely sustained throughout testing.

We also performed these same tests in a separate group of animals that were not exposed to the running wheel to determine the effects of activity on the other pain-related behaviors. Wheel activity did not appear to alter grip strength after I/R in any of our conditions, so data were combined from these two groups in this assay to enhance statistical power (naive/sham, $n=25$; control $\mathrm{I} / \mathrm{R}, n=40 ; \mathrm{I} / \mathrm{R}$ only, $n=15$; PenCON $+\mathrm{I} / \mathrm{R}, n=25$; PenIL1r1 $+\mathrm{I} / \mathrm{R}, n=14)$. However, it is important to note that this other cohort of mice did not show a full resolution of spontaneous/ ongoing pain or evoked mechanical hypersensitivity back to naive/sham levels by D3, although defects had significantly improved from the D1 time point (data not shown).
IL1r1 knock-down inhibits injury-induced changes in afferent chemosensitivity and mechanical threshold We then performed our ex vivo intracellular muscle afferent recording to determine specific response properties to thermal, mechanical, and chemical stimulation in these groups. Similar to our previous results (Ross et al., 2014), we found that control I/R injured muscle results in significantly fewer muscle sensory neurons $(n=3 / 56)$ that are responsive to only the "low" metabolites (metaboreceptors) compared with either naive $(n=8 / 34 ; p=$ $0.018)$ or PenIL1r1 + I/R mice $(n=10 / 47 ; p<0.001$, Fisher's exact test; Fig. 2a). Furthermore, the proportion of metabolite-responsive cells responding to either "high" (metabonociceptors) or both metabolite solutions was significantly higher in the control I/R condition $(n=17 / 20)$ than in either the naive $(n=5 / 13)$ or the PenIL1r1 $+\mathrm{I} / \mathrm{R}(n=13 / 23)$ conditions $\left(p<0.001, \chi^{2}\right.$ analysis $)$.

Although we assessed multiple response properties in our functionally characterized afferents, similar to our previous report (Ross et al., 2014), the only two response characteristics that were found to be altered by $\mathrm{I} / \mathrm{R}$ were mechanical thresholds and mean peak IF to low metabolite stimulation of the muscles (Fig. $2 b-d)$. Mechanical thresholds in muscle afferents were significantly lower after control I/R $(1.34 \pm 0.49 \mathrm{~g} ; n=17)$ than in either the naive $(3.57 \pm 0.9 \mathrm{~g} ; n=14 ; p<0.05)$ or PenIL1r1 + I/R conditions $(3.67 \pm 0.95 \mathrm{~g} ; n=15 ; p<0.05$, Kruskal-Wallis with Dunn's test). Although mechanical thresholds significantly decreased after I/R and were restored with IL1r1 inhibition, the peak firing of mechanically sensitive afferents to stimulation of the muscles did not differ between groups (naïve, $50.78 \pm 12.06$ $\mathrm{Hz}, n=15$; control I/R, $33.37 \pm 6.57 \mathrm{~Hz}, n=36$; PenIL1r1 $+\mathrm{I} / \mathrm{R}$, $36.41 \pm 9.97 \mathrm{~Hz}, n=20$; Kruskal-Wallis, $p>0.05)$. The mean peak IF to low metabolites was also significantly altered between groups (Fig. 2d); however, whereas control I/R afferents showed increased firing $(9.73 \pm 2.97 \mathrm{~Hz}, n=14)$ compared with naive 
a
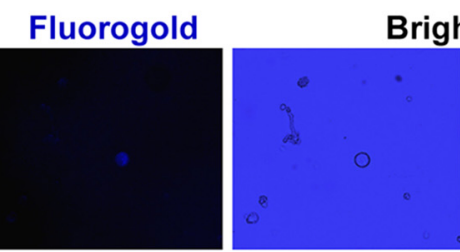

Brightfield

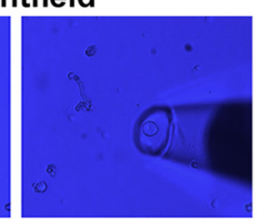

d
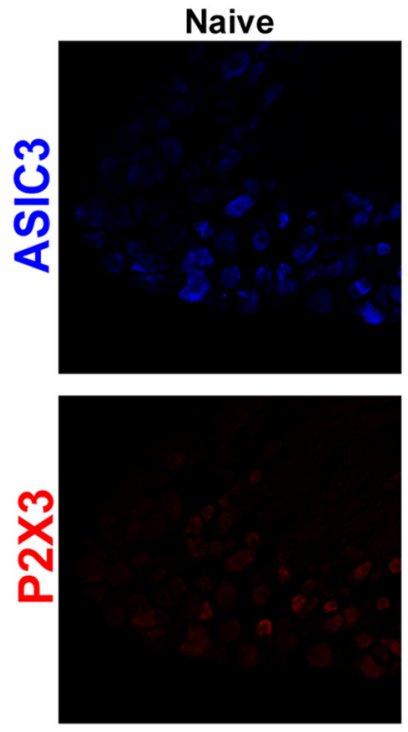

b
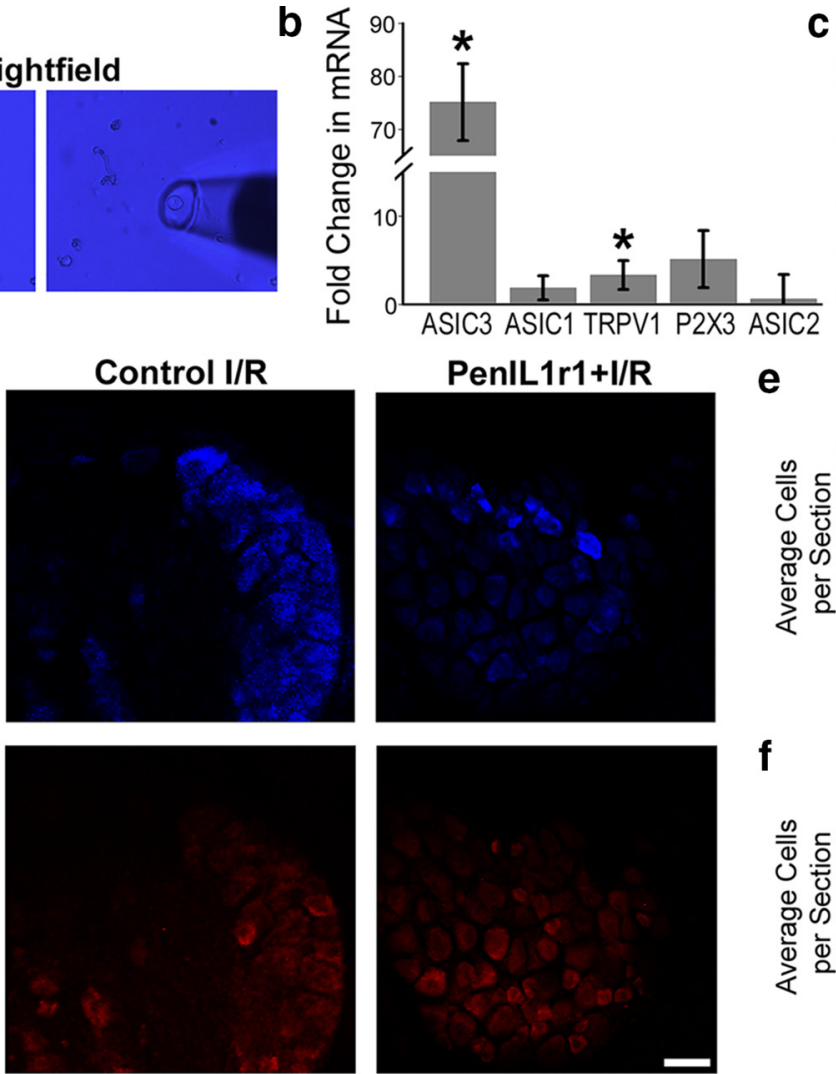
PenlL1r1+l/R
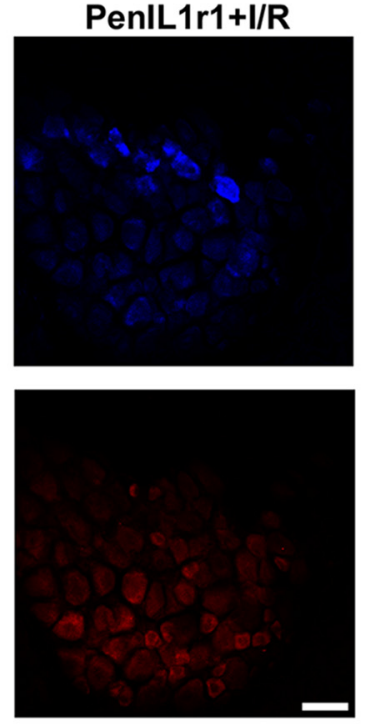

e

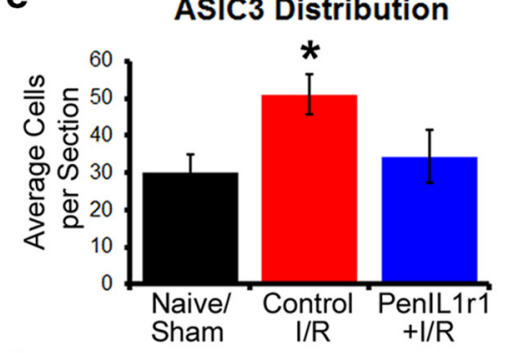

f

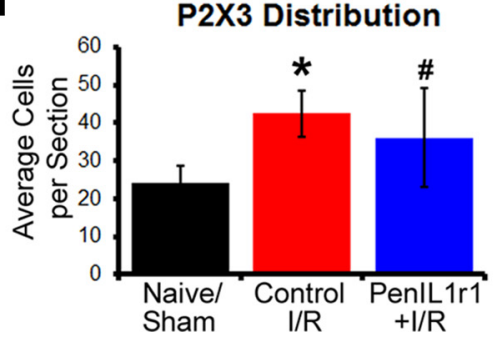

Figure 3. ASIC3 upregulation after I/R is linked to increased IL1 $\beta$ and IL $1 r 1$ expression. $\boldsymbol{a}$, FG-labeled primary afferents from DRG cultures $(n=3-6)$ for single-cell qPCR. $\boldsymbol{b}$, Cells incubated in IL1 $\beta$-enriched medium showed significant upregulation of ASIC3 and TRPV1, but not P2X3, ASIC1, or ASIC2, compared with untreated cells ( $n=10-12$ cells per treatment). c, Verification of LYS internal control for use in single-cell real-time PCR. We performed our single-cell qPCR analysis from whole DRG RNA samples diluted to varying starting concentrations $(5,10$, and $100 \mathrm{pg})$ containing the same amount of spike RNA (LYS: 1000 copies). Analysis of these postamplification samples shows that, even when varying the total starting RNA concentration (and thus the Ct values for GAPDH), we still obtain a consistent level of the spike RNA. $\boldsymbol{d}$, Representative immunohistochemical staining of ASIC 3 or P2X3 protein in whole DRGs from naive, control I/R, and IL1r1 conditions are shown. ASIC3-immunopositive cells are significantly increased in the control I/R condition over both the naive and PenIL $1 \mathrm{r} 1+\mathrm{I} / \mathrm{R}$ conditions, which did not differ (e). Increased P2X3 after I/R was not affected by IL $1 \mathrm{r} 1$ knock-down $(\boldsymbol{f})$. Data are represented as mean \pm SEM and were analyzed via one-way ANOVA with Tukey's post hoc test. ${ }^{*} p<0.05$ compared with naive or untreated; $\# p>0.05$ compared with naive and control I/R. Scale bar for all images, $60 \mu \mathrm{m}$.

afferents $(1.07 \pm 0.42 \mathrm{~Hz}, n=9 ; p<0.05)$, inhibition of IL1 $1 \mathrm{r} 1$ in muscle afferents did not alter this change (PenIL1r1 $+\mathrm{I} / \mathrm{R}$, $7.33 \pm 2.63 \mathrm{~Hz}, n=13, p>0.05)$. No differences in firing to cold or hot saline or high metabolites were detected in any group nor were any differences in mechanically, thermally, or silent fiber prevalence found ( $p>0.05 ; \chi^{2}$; Fig. $2 e, f ;$ data not shown). After $3 \mathrm{~d}$, mice with I/R did not differ from the D1 control I/R or naive groups in proportions of metabolite responsive afferents (low, $n=4 / 18$; high/both, $n=4 / 18)$, low $\operatorname{IF}(2.72 \pm 1.46 \mathrm{~Hz}, n=5, p>$ $0.05)$, or mechanical threshold (1.47 $\pm 0.59 \mathrm{~g}, n=8, p \geq 0.13$ ), suggesting a partial recovery in these properties, which is consistent with the behavioral data $(p>0.05$, Kruskal-Wallis test).

\section{IL1 $\beta$ treatment of primary afferents in vitro upregulates}

ASIC3 gene expression in single cells

To determine the specific mechanistic role of IL1 $\beta$ in regulating muscle afferent sensitization and subsequent pain-related behaviors, we retrogradely labeled primary afferents by injecting fluorogold into the forepaw muscles of mice $(n=3-6)$ and treated dissociated C7/C8/T1 DRGs with IL1 $\beta$-enriched medium. We then randomly collected and analyzed these labeled cells $(n=$ 10-12 per condition) with single-cell real-time PCR for likely mediators of muscle afferent sensitization (Molliver et al., 2005; Ross et al., 2014; Fig. 3a-c). Compared with cells treated with medium only, IL1 $\beta$-treated afferents showed distinct upregula- tion of ASIC3 (75.12 \pm 7.23 -fold increase, $p=0.02)$ and TRPV1 (3.31 \pm 1.64 -fold increase, $p=0.03)$, but did not alter significantly the expression of the ATP-responsive ion channel P2X3 or the other acid-sensing ion channels, ASIC1 and ASIC2 (5.12 \pm $3.22,1.86 \pm 1.36$, and $0.62 \pm 2.76$, respectively, $p>0.05$; oneway ANOVA with Tukey's test; Fig. $3 b$ ). Our normalization and quantification methods for single-cell real-time PCR were validated by assessing the expression of GAPDH and the LYS spike RNA in DRG samples of distinct starting concentrations. When performing amplification of DRG RNAs with different starting concentrations, we detected corresponding changes in $\mathrm{Ct}$ for GAPDH, but no differences in the added LYS gene were detected (Fig. $3 c$ ).

Because we found previously that I/R injury upregulated ASIC3 and P2X3 in the DRGs in vivo, but did not induce TRPV1 expression (Ross et al., 2014), we assessed ASIC3 and P2X3 specifically in the DRGs in vivo in our groups (Fig. $3 d$ ). We found that the de novo ASIC3 protein expression detected immunocytochemically after control $I / R$ in whole DRGs (mean number of cells per section: naïve, $30.1 \pm 4.87 ; \mathrm{I} / \mathrm{R}$, $51 \pm 5.41 ; p<0.05)$ was eliminated with IL1r1 knock-down $($ PenIL1r1 $+\mathrm{I} / \mathrm{R}, 34.3 \pm 7.12 ; p=0.025$ vs control $\mathrm{I} / \mathrm{R}, p=$ 0.555 vs naive). However, $\mathrm{P} 2 \mathrm{X} 3$ expression in mice with IL1r1 knock-down was no different from naive or control I/R (mean number of cells per section: naïve, $24 \pm 4.51$; I/R, $42.52 \pm 6.1$, 
a

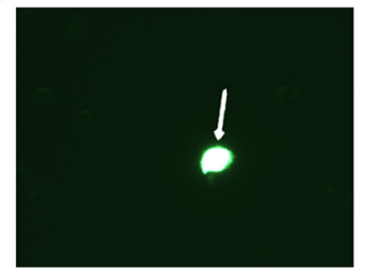

d

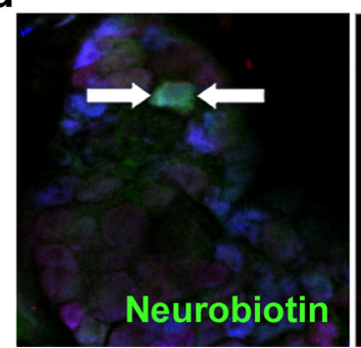

b

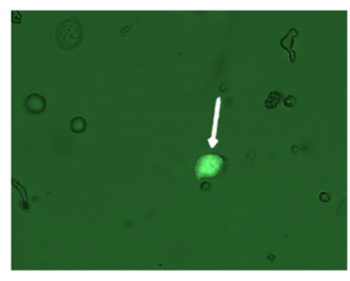

High Metabolites

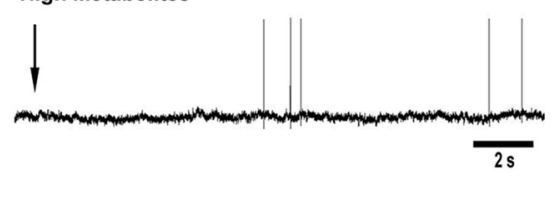

C Amplification Plot

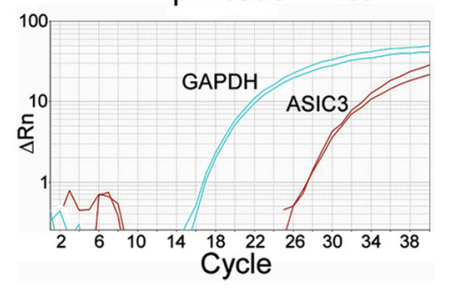

e
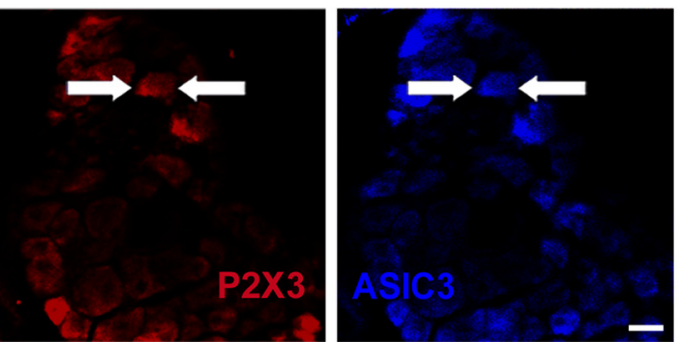

High Metabolites

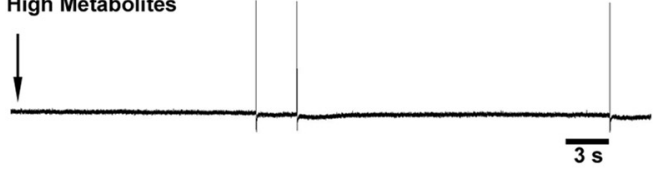

Figure 4. ASIC3 expression in naive animals is present in metabo-nociceptors. $\boldsymbol{a}$, Examples of a Lucifer yellow-labeled muscle afferent recovered in vitro after characterization via ex vivo recording $(n=6) . \boldsymbol{b}$, This "high" responder was found to be ASIC3-positive at the mRNA level. Presence of GAPDH verified appropriately amplified cDNAs in the single cell. $\boldsymbol{c}$, An intracellularly stained (neurobiotin, green) and physiologically characterized muscle afferent (arrows) from uninjured tissue that was responsive to high metabolites (d, $\boldsymbol{e}$ ) was also immunopositive for both ASIC3 (blue) and P2X3 (red). Scale bar for all images, $60 \mu \mathrm{m}$.

$p=0.03$ vs naive; PenIL1r $1+\mathrm{I} / \mathrm{R}, 36.1 \pm 13.1, p>0.25 \mathrm{vs} \mathrm{I/R}$ and naive; Fig. $3 d-f$ ).

\section{Injury-induced expression of ASIC3 in metaboreceptors is attenuated by IL1r1 knock-down}

These results suggested that enhanced ASIC3 expression specifically after I/R injury in sensory neurons could be downstream of IL1 $\beta /$ IL1r1 signaling from the muscles. We thus performed phenotypic analysis on our functionally defined muscle afferents using two different strategies. First, we filled selected functionally characterized muscle afferents intracellularly during ex vivo recording with Lucifer yellow, dissociated the respective DRG in vitro, and performed single-cell real-time PCR analysis on the identified cells (Fig. 4a). Next, we performed similar analysis of functionally defined cells, but analyzed the neurochemical content of select fibers using immunocytochemistry. We validated our previous work (Ross et al., 2014) in that mechanically sensitive group III/IV muscle afferents, as well as high metabolite responders contained ASIC3, whereas low metabolite responders did not (Figs. 4, $5 a-d$, Table 3$)$. Although, after I/R injury, metaboreceptors were found to express ASIC3 (Fig. $5 e-h$, Table 3 ), afferenttargeted IL1r1 knock-down prevented this upregulated expression of ASIC3 in these cell types and restored the normal phenotypic proportions to that detected in naive mice (Fig. $5 i-p$, Table 3). P2X3 was found to be localized in small proportions to all functionally defined cell types (Table 3). Finally, there was no notable variation between groups when staining cold or heat responsive fibers and two silent fibers were also labeled and characterized within the control I/R condition, but both were found to be immunonegative for P2X3 and ASIC3.

Inhibition of ASIC3 attenuates behavioral effects of ischemia and reperfusion injury

To elucidate the specific role of ASIC3, we again used our nerve-specific siRNA knock-down strategy in conjunction with I/R injury. We first confirmed that IL1r1 knock-down attenuated the injury-induced ASIC3 protein expression in the DRGs in vivo ( $p \leq 0.025$, I/R compared with all groups). Then, we verified that our siRNA injection strategy was also effective in knocking down I/R-induced ASIC3 protein expression directly in the DRGs (Fig. 6a) and performed our behavioral assessments in mice with direct inhibition of ASIC3 upregulation after I/R (PenASIC3 + I/R). The PenASIC3 + I/R-treated mice $(n=8)$ did not display increased guarding behaviors like that previously described in the control I/R condition ( $p=0.016$; vs naive/sham $p=0.36$; Fig. $6 b)$. Naive/ sham and PenASIC3 $+\mathrm{I} / \mathrm{R}$ animals were no different on D1 $(p=0.104)$ or D3 $(p>0.8)$. Furthermore, PenASIC3 $+\mathrm{I} / \mathrm{R}$ animals did not show alterations in guarding behaviors over time (BL: $0.0 \pm 0.0, \mathrm{D} 1: 0.15 \pm 0.05, \mathrm{D} 3: 0.09 \pm 0.05 ; p \geq$ $0.169)$, similar to that seen in naive/sham and PenIL1r1 $+\mathrm{I} / \mathrm{R}$ mice (Fig. 1). PenASIC3 + I/R animals also failed to display the reduced mechanical withdrawal thresholds (BL: $2.3 \pm$ 0.45 g. D1: $1.6 \pm 0.33$ g, D3: $1.2 \pm 0.13$ g; $p \geq 0.712$; Fig. $6 c$ ) found in the control I/R animals on D1 $(p=0.038)$.

During assessment of grip strength (Fig. $6 d$ ), we found that, although there appeared to be some improvement between D1 and D3 in the PenASIC3 + I/R condition (D1: $-4.09 \pm 2.96 \%$ from BL, D3: $5.13 \pm 5.06 \%, n=22 ; p<0.1)$, the impairment in grip strength was not significantly different from naive/ sham $(p=0.55)$ or control I/R mice $(p=0.41)$ at D1, thus indicating a partial rescue of function. Regarding measurement of voluntary activity (Fig. $6 e, f$ ), PenASIC3 + I/R animals performed similarly to naive/sham and PenIL1r1 + I/R animals (Fig. 1). PenASIC3 + I/R mice ran significantly greater distances (6744 \pm 823 revolutions, $p=0.003$ ) than control I/R mice on D1. They were also no different from any group in distance traveled on D3 (4596 \pm 1005 revolutions, $p \geq 0.25$ ). Interestingly, they ran at consistently higher velocities (D1: $3.96 \pm 0.53 \mathrm{~m} / \mathrm{min}, \mathrm{D} 3: 3.72 \pm 0.8 \mathrm{~m} / \mathrm{min}$ ) than either control I/R or naive/sham animals $(p=0.003,0.043$, respectively). 

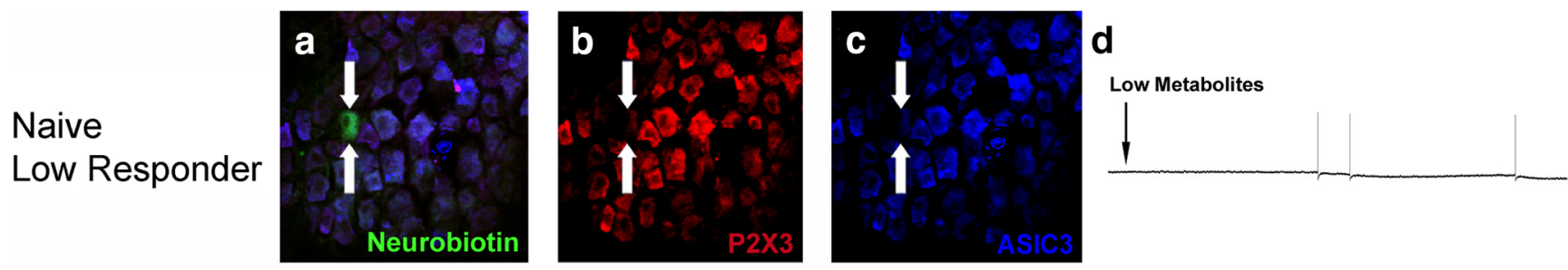

\section{Control I/R Low/High Responder}
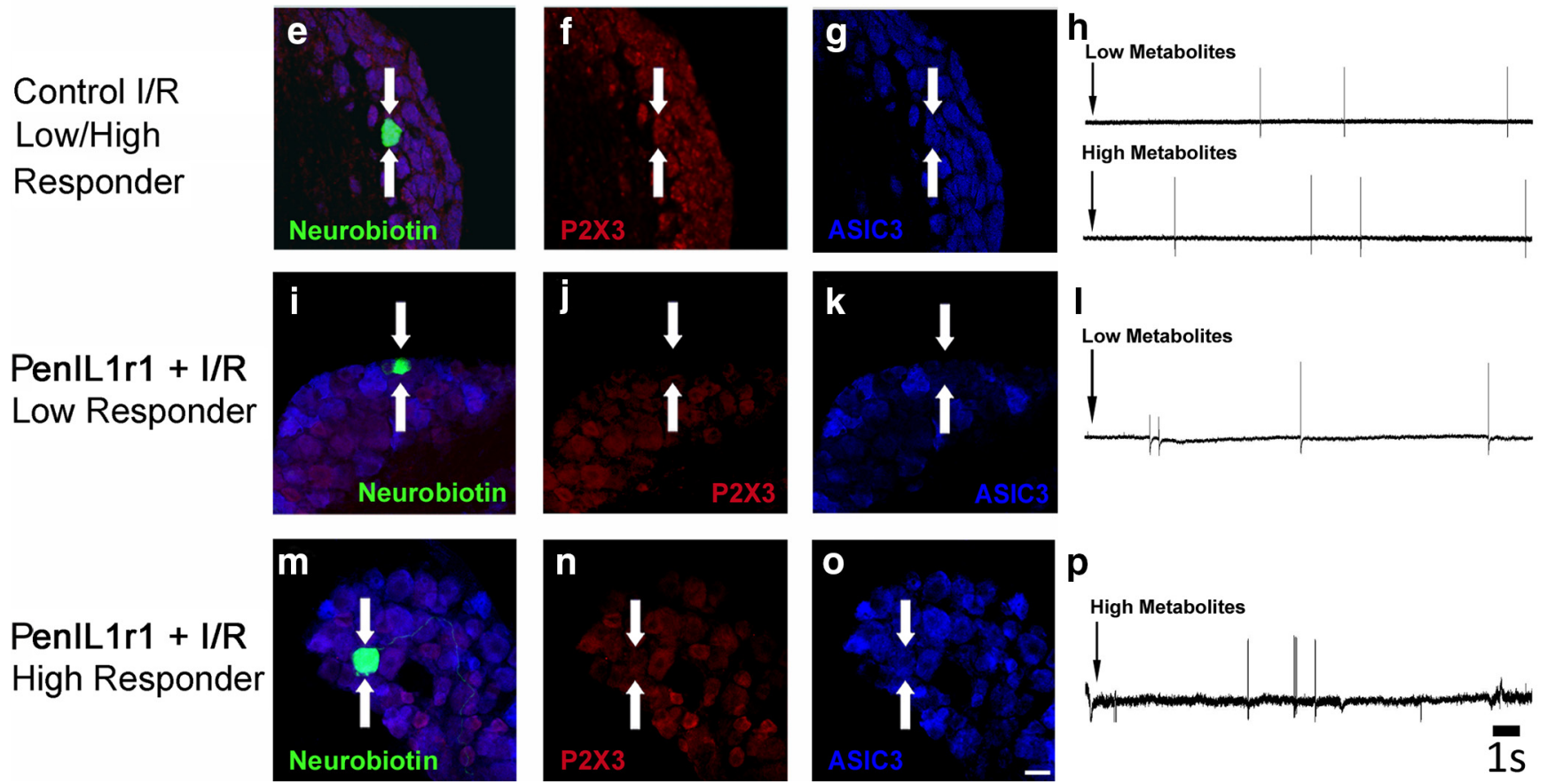

Figure 5. Neurochemical identification of single metabolite-responsive muscle afferents recovered from ex vivo recordings in each condition. A neurobiotin-labeled (green, arrows) naive muscle afferent $(\boldsymbol{a})$ that was responsive to low, but not high ( $\boldsymbol{d})$, metabolites was found to be immunonegative for both P2X3 (red) and ASIC3 (blue; $\boldsymbol{b}, \boldsymbol{c}$ ). After $1 \mathrm{~d}$ I/R, a chemosensitive muscle afferent ( $\boldsymbol{e}$ ) sensitive to both metabolite solutions $(\boldsymbol{h})$ was immunopositive for P2X3 and ASIC3 $(\boldsymbol{f}, \boldsymbol{g})$. Characterized and labeled metabolite-sensitive afferents from the PenIL $1 \mathrm{r} 1+\mathrm{I} / \mathrm{R}$ conditions showed differing neurochemical phenotypes based on their metabolite selectivity $(\boldsymbol{i}-\boldsymbol{p})$. A neuron responsive to low metabolites was found to be P2X3 and ASIC 3 immunonegative $(\boldsymbol{j}, \boldsymbol{k})$, whereas a high responder from this condition was P2X3 and ASIC3 immunopositive $(\boldsymbol{n}, \boldsymbol{0})$. Scale bar for all images, $60 \mu \mathrm{m}$.

Table 3. Immunostaining of ASIC3 and P2X3 in functionally characterized muscle afferents recovered from the ex vivo recording preparations

\begin{tabular}{lllll}
\hline \multirow{2}{*}{ Response type } & Condition & ASIC3 + & P2X3 + & $\begin{array}{l}\text { ASIC3+l } \\
\text { P2X3+ }\end{array}$ \\
\hline Mechanoreceptors & Naive/sham & $3 / 5$ & $3 / 6$ & $3 / 6$ \\
& Control I/R & $4 / 5$ & $2 / 5$ & $1 / 5$ \\
& PenIL1r1 + I/R & $0 / 6$ & $2 / 6$ & $0 / 6$ \\
& PenASIC3 + I/R & $0 / 1$ & $1 / 1$ & $0 / 1$ \\
Metabo-nociceptors & Naive/sham & $3 / 4$ & $3 / 4$ & $2 / 4$ \\
(high responders only) & Control I/R & $1 / 5$ & $3 / 5$ & $1 / 5$ \\
& PenIL1r1 + I/R & $2 / 3$ & $0 / 3$ & $0 / 3$ \\
& PenASIC3 + I/R & $0 / 2$ & $1 / 2$ & $0 / 2$ \\
Metaboreceptors (low & Naive/sham & $0 / 3$ & $0 / 4$ & $0 / 4$ \\
responders and both & Control I/R & $3 / 7$ & $2 / 6$ & $2 / 6$ \\
responders) & PenIL1r1 + I/R & $0 / 4$ & $2 / 4$ & $0 / 4$ \\
& PenASIC3 + I/R & $0 / 3$ & $0 / 3$ & $0 / 3$ \\
\hline
\end{tabular}

Italics indicate discrepancies in ASIC3 expression between conditions.

\section{ASIC3 knock-down blocks I/R-induced changes in afferent} response properties and neurochemical phenotypes similarly to IL1r1 knock-down

We then found, using ex vivo recording, that the alterations in proportions of metabolite responders observed after I/R were also completely blocked by nerve-specific inhibition of ASIC3. As found in the PenIL1r1 + I/R condition (Fig. 2), the population of metaboreceptors in PenASIC3 $+\mathrm{I} / \mathrm{R}(n=10 / 51)$ was restored to naive levels ( $p=0.004$ vs control I/R, Fisher's exact test; Fig. 7a), as were the proportions of metabo-nociceptors and cells responding to both metabolite solutions $(n=11 / 21 ; p<0.001$ vs control I/R, $\chi^{2}$ ). Similar to the IL1r1 knock-down (Fig. 2), decreased mechanical thresholds induced by I/R (Fig. $7 b, c)$ were also blocked in the PenASIC3 $+\mathrm{I} / \mathrm{R}$ condition $(4.77 \pm 0.79 \mathrm{~g}, n=$ $13 ; p>0.05$ vs naive and control I/R, Kruskal-Wallis test); however, the increased mean peak instantaneous firing frequency to low metabolites was unaffected by afferent-specific ASIC3 knock-down $(14.37 \pm 7.25 \mathrm{~Hz}, n=12 ; p>0.05$ vs all groups; Fig. $7 d$ ). No changes were observed in firing to high metabolites (Fig. $7 e$ ) or in the proportions of mechanically, cold- or heat-sensitive fibers, or silent fibers (Fig. 7f). Finally, we performed immunocytochemical analysis of these functionally defined muscle afferents and again found that low responders were ASIC3 negative (Fig. $7 g, h$ ), whereas high responders remained ASIC3-positive similar to that detected in naive mice (Figs. 4, 5, Table 3).

Activated c-Jun $\mathrm{N}$-terminal kinase signaling promotes ASIC3 expression

After characterizing the tightly correlated expression patterns and functions of IL1 $\beta$, IL1r1, and ASIC3 in group III and IV muscle afferents after ischemic injury, we wanted to determine the potential mechanism through which IL1 $\beta$ may modulate ASIC3 expression. Therefore, we performed additional analyses of potential signaling mediators in the mitogen activated protein 

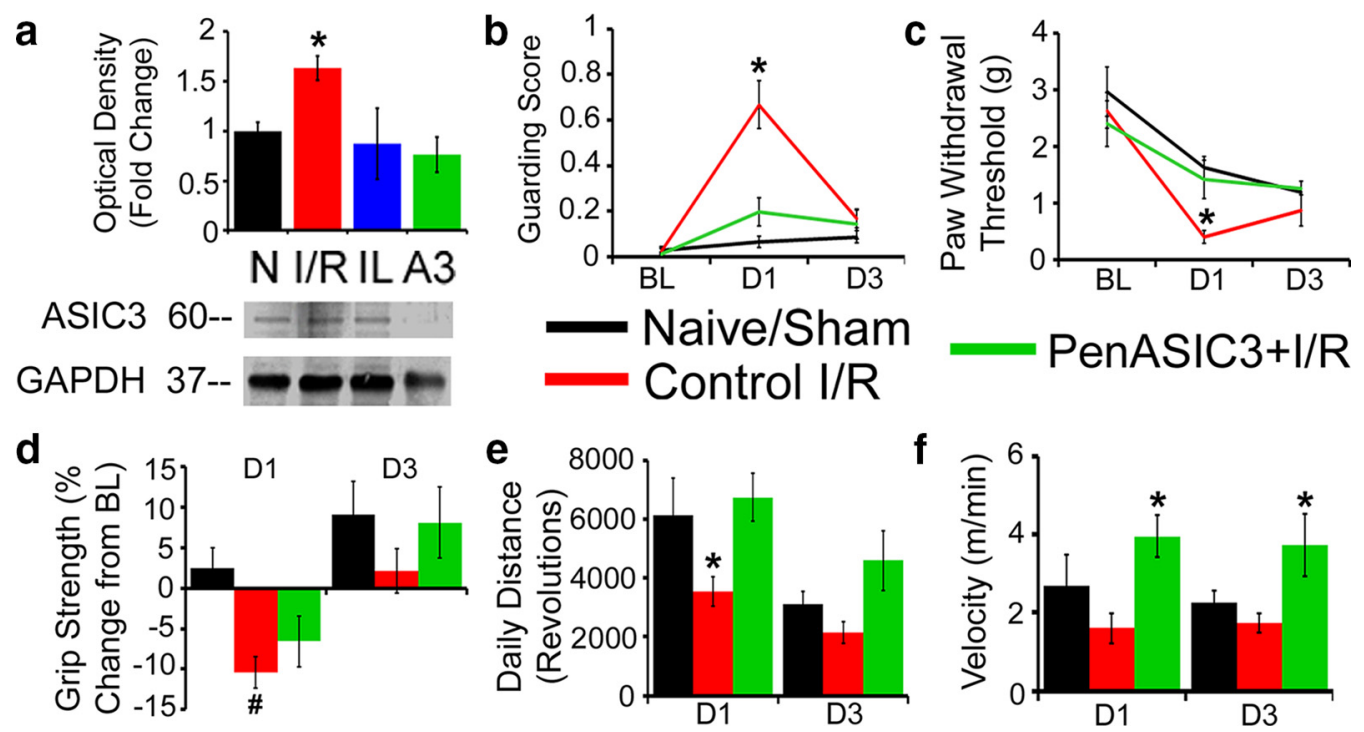

Figure 6. ASIC3 inhibition through siRNA-mediated knock-down attenuates I/R-induced alterations in voluntary activity and other pain-related behaviors. Total protein expression of ASIC 3 is increased in the affected C7/C8/T1 DRGs after I/R (a), but channel upregulation is blocked by nerve-specific siRNA knock-down of either IL $1 \mathrm{r} 1$ or ASIC3 $(n=3)$. $\boldsymbol{b}$, PenASIC3 $+\mathrm{I} / \mathrm{R}$ animals were no different from naive/sham animals in spontaneous pain behaviors measured by the paw-guarding assay on D1 or D3 and they did not significantly change from BL measurements at either time point. c, Paw withdrawal thresholds in the PenASIC3 + I/R group also did not change from BL levels; however, the I/R-induced grip strength deficit was not completely prevented by ASIC3 knock-down (d) because PenASIC3 $+\mathrm{I} / \mathrm{R}$ animals did not differ significantly from either control I/R or naive/sham animals at D1, even though there appeared to be significant improvement between D1 and D3 in the PenASIC3 + I/R condition. On D1, PenASIC3 + I/R animals ran significantly greater distances $(\boldsymbol{e})$ than control I/R mice. They also ran at higher velocities $(\boldsymbol{f})$ than either the naive/sham or control I/R groups. This velocity difference also performed to D3 compared with the control I/R animals, but not to any other group. Data are represented as mean \pm SEM and were analyzed via one-way ANOVA with Tukey's post hoc or two-way RM ANOVA with Holm-Sidak post hoc tests. $n \leq 8$ for each behavioral task. ${ }^{*} p<0.05$ compared with all other conditions; \#p $<0.05$ compared with naive/sham.

kinase (MAPK) family [extracellular signal related kinase (ERK) $1 / 2$, p38 MAPK] and the SRC signaling and JNK pathways. No significant labeling of naive DRGs was found when assessing activated/phosphorylated (p-)-ERK1/2, p-p38 or p-SRC (data not shown), which would have significantly hindered the ability to fully quantify cell numbers after I/R. However, we found that p-JNK not only showed detectable labeling in naive DRGs, but also I/R injury-related upregulation, so we focused on this potential signaling mediator (Fig. 8). We determined that p-JNK is significantly upregulated in the DRGs $3 \mathrm{~h}$ after I/R compared with naive controls (mean number cells per section: naive: $5.67 \pm$ $0.6,3$ h I/R: $28.56 \pm 3.4, p<0.001$; Fig. $8 a, b)$ and was heavily colocalized with ASIC3 (mean ASIC3 cells coexpressing p-JNK: naive: $21.6 \pm 1.8 \%, 3 \mathrm{~h} \mathrm{I} / \mathrm{R}: 47.5 \pm 0.8 \%, p<0.001$; Fig. $8 a, c$ ). However, these changes in expression return to naive levels at $24 \mathrm{~h}$ after I/R (p-JNK + cells: $6.67 \pm 0.6$; ASIC3/p-JNK coexpression: $17.6 \pm 1.4 \%$; both $p>0.05$ compared with naive and $p<$ 0.001 vs $3 \mathrm{~h} \mathrm{I} / \mathrm{R})$.

We then cultured retrogradely labeled afferents from FGinjected forepaw muscles in growth media with or without IL1 $\beta$ enrichment, finding initially that IL1 $\beta$ treatment increased the percentage of p-JNK positive, FG back-labeled afferents directly (untreated: $56.5 \%$, IL1 $\beta$-treated: $81.8 \%, p<0.05$ ) in vitro. Furthermore, IL1 $\beta$ treatment was found to increase ASIC 3 mRNA significantly $(75.12 \pm 7.23$ fold, $p=0.02)$ in these single cells, which was inhibited when IL1 $\beta$-treated cells were coincubated with the JNK inhibitor SP600125 (Figs. 3b, 8f; IL1 $\beta+$ SP600125: $5.07 \pm 4.79$ fold, $p=0.365$ vs untreated; SP600125 only: $0.45 \pm$ 5.63 fold, $p=0.531$ ). To confirm more specifically that our effects were not due to other potential signaling pathways linked to IL1 $\beta /$ IL1r1, we also performed control experiments to assess whether IL1 $\beta$ may be mediating its effects on ASIC3 expression via the NF $\kappa$ B pathway (O'Neill and Greene, 1998). To this end, we treated afferents retrogradely labeled by FG from the muscles with IL1 $\beta$ and the NF $\kappa$ B inhibitor CAPE (Chiechio et al., 2006) and found that CAPE treatment had no effect on IL1 $\beta$-mediated ASIC3 upregulation (IL1 $\beta+$ CAPE: $73.03 \pm 4.92$ fold, $p=0.343$ vs untreated; CAPE only: $23.77 \pm 4.85, p=0.041)$. Using MatInspector software (Genomatix), we determined that JNKmediated ASIC3 expression is likely due to the fact that ASIC3 has multiple AP1/Jun transcription factor-binding sites in its upstream promoter region (Fig. $8 g$ ).

\section{Discussion}

Muscle pain is a widespread, yet poorly defined clinical phenomenon (Mense, 2003; 2008). Many muscle pain disorders have been linked to problems of peripheral perfusion and the resulting ischemic-like states have been linked, not only to pain, but to tissue inflammation as well (Blaisdell, 2002; Coderre et al., 2004; Eisenhardt et al., 2012), which could be a significant underlying cause of the observed hypersensitivity in these muscle pain disorders. Using our previously defined (Ross et al., 2014) model of ischemic myalgia ( $\mathrm{I} / \mathrm{R}$ ) in conjunction with nerve-specific siRNA inhibition (Jankowski et al., 2009b, 2010, 2012a,b) of injuryinduced ASIC3 or IL1r1 upregulation, we further explored the role of muscle-derived signaling molecules on afferent sensitization and subsequent manifestation of pain-like behaviors. With this study, we have established a mechanism through which ischemia-induced inflammatory cytokine signaling (IL1 $\beta /$ IL1r1) from the muscles modulates the dynamic changes in acid-sensing ion channel protein expression in the primary muscle afferents, leading to ischemic myalgia-like behaviors, potentially via a c-Jun $\mathrm{N}$-terminal kinase-activated pathway.

\section{Inflammation and ischemic myalgia}

Patients with ischemia-related myalgia often report ongoing pain, mechanical hypersensitivity, muscle weakness, and a reduction in overall activity (Blaisdell, 2002; Mense, 2003; Katz et al., 

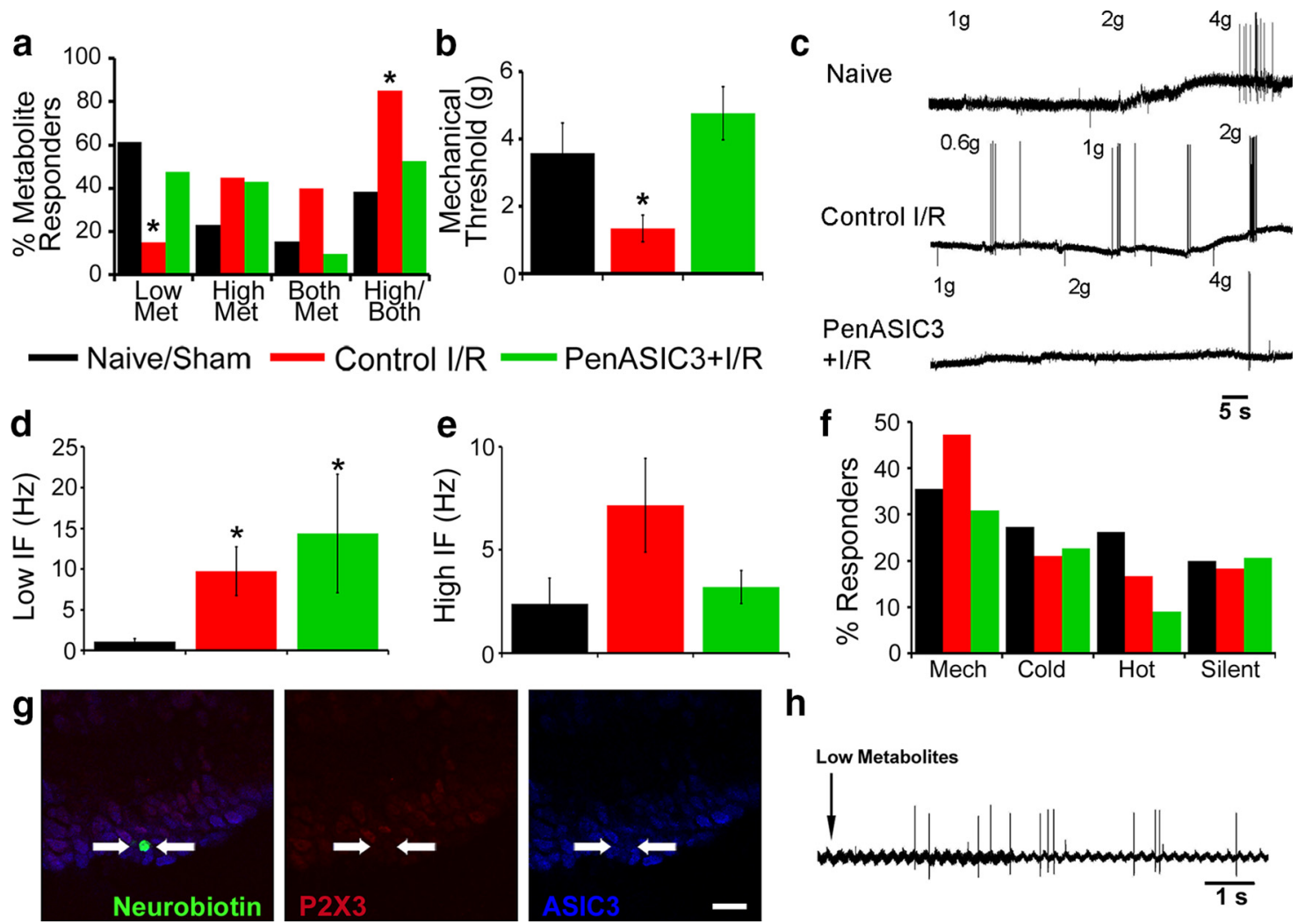

h

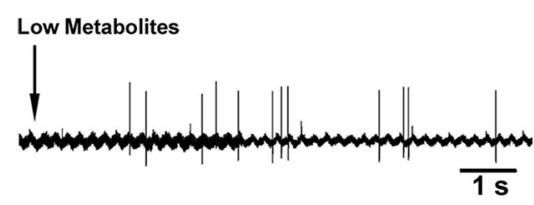

Figure 7. Inhibition of post-I/R ASIC3 upregulation prevents injury-induced alterations in muscle afferents. $\boldsymbol{a}$, Similar to siRNA-mediated IL1r1 knock-down, group III and IV primary muscle afferent phenotypes in the PenASIC3 + I/R condition are no different from the naive condition as assessed with ex vivo recording. $\boldsymbol{b}, A S I C 3 \mathrm{knock}$-down also prevents the I/R-associated decrease in mechanical threshold. $\boldsymbol{c}$, Examples of responses to mechanical deformation of the muscles in naive/sham, control I/R, and PenASIC3 + I/R mice. $\boldsymbol{d}$, Although I/R caused increased firing to low metabolites, ASIC3-targeting siRNA injection did not restore mean peak instantaneous firing frequencies to this metabolite solution back to naive levels. $\boldsymbol{e}$, Instantaneous frequency to high metabolites was also not different in any group. $f$, I/R did not alter total numbers of thermally sensitive, mechanically responsive, or silent fibers and siRNA knock-down of ASIC 3 also did not affect these phenotypes. $\boldsymbol{g}$, A neurobiotin-labeled (green, arrows) muscle afferent recovered from a PenASIC3 + I/R preparation that was responsive to low, but not high ( $\boldsymbol{h}$ ), metabolites was found to be immunonegative for both P2X3 (red) and ASIC3 (blue). Data are represented as mean \pm SEM and were analyzed via $\chi^{2}$ analysis or Kruskal-Wallis one-way ANOVA on ranks with Dunn's test. * $p<$ 0.05 compared with naive. Scale bar for all images, $60 \mu \mathrm{m}$.

2007; Mense, 2008; Zempsky et al., 2013). Here, we assessed these same features in a rodent model of I/R. Although none of these tasks individually can describe the extent of myalgia in mice, when combined, they allowed us to detect subtle behavioral differences in ischemic muscle injury paradigms and allow us to draw conclusions about the animals' deep tissue "pain" (Seo et al., 2010; Xu and Brennan, 2010; Ross et al., 2014). Control I/R animals displayed increased mechanical hypersensitivity and guarding behaviors, as well as decreased grip strength and voluntary activity, compared with naive/sham mice, recapitulating clinical manifestations of ischemic myalgia (Figs. 1, 6). Furthermore, all I/R-induced behavioral deficits were inhibited by afferent-targeted knock-down of either ASIC3 or IL1r1, suggesting that the two receptors may share a common pathway to mediate the majority of injury-induced nociceptive-like behaviors. Interestingly, the only difference between the two siRNA conditions was that voluntary activity was significantly increased in PenASIC3 + I/R, but not PenIL1r1 + I/R, mice compared with control I/R animals (Figs. 1, 6). This is likely due to other roles of IL1r1, but may also be caused by a more direct effect of ASIC3 on this particular behavior.

Previous data have linked inflammatory cytokines, including IL1 $\beta$, to painful sensations from the muscles (Ferreira et al., 1988; Dina et al., 2008; Noma et al., 2013; Alvarez et al., 2014). Blocking IL1 $\beta$ prevents inflammation-induced hypersensitivity, whether provoked by carrageenan or systemic administration of exoge- nous IL1 $\beta$ (Ferreira et al., 1988), and IL1r1 antagonists that are used to treat rheumatoid arthritis-related inflammation have also been shown to reduce pain (Hallegua and Weisman, 2002). IL1 $\beta$ is a known modulator of gene expression through numerous pathways (McMahon et al., 2015; O’Neill and Greene, 1998) and, in PenIL1r1 + I/R animals, both IL1r1 and ASIC3 upregulation were inhibited after I/R (Figs. 1, 7), suggesting that ASIC3 is downstream of IL1 $\beta /$ IL $1 r 1$. In support of this notion, Mamet et al. (2002) have shown that IL1 $\beta$ stimulates DRG expression of ASIC3 in vitro. When incubating cultured cells with solutions containing IL1 $\beta$ before patch-clamp electrophysiology, they not only showed a trend toward greater numbers of $\mathrm{pH}$-responsive cells, but also found significantly increased amplitudes of ASIClike currents. Here, we also found that primary afferents treated with IL1 $\beta$ in culture show similar increases in ASIC3, but not ASIC1 or 2 , thus strengthening IL1 $\beta$ 's role in injury-induced expression of ASIC3 specifically. Although IL1 $\beta$ treatment induced TRPV1 upregulation in vitro, TRPV1 was not upregulated in the affected DRGs after I/R (Ross et al., 2014). Therefore, I/Rinduced changes in muscle afferent function via IL1 $\beta$ are not likely to be linked to TRPV1 upregulation.

Furthermore, a number of studies have linked ASIC3 to afferent sensitization in other injury models of muscle pain (Benson et al., 1999; Immke and McCleskey, 2001a; 2001b; Sluka et al., 2003; Naves and McCleskey, 2005; Yagi et al., 2006; Benson and McCleskey, 2007; Sluka et al., 2007; Birdsong et al., 2010; Gautam 
a
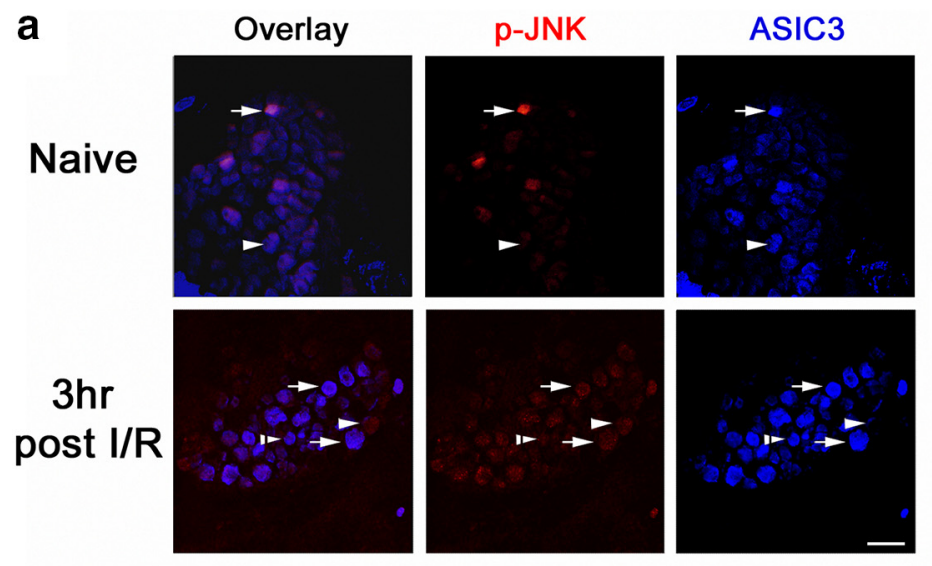

b
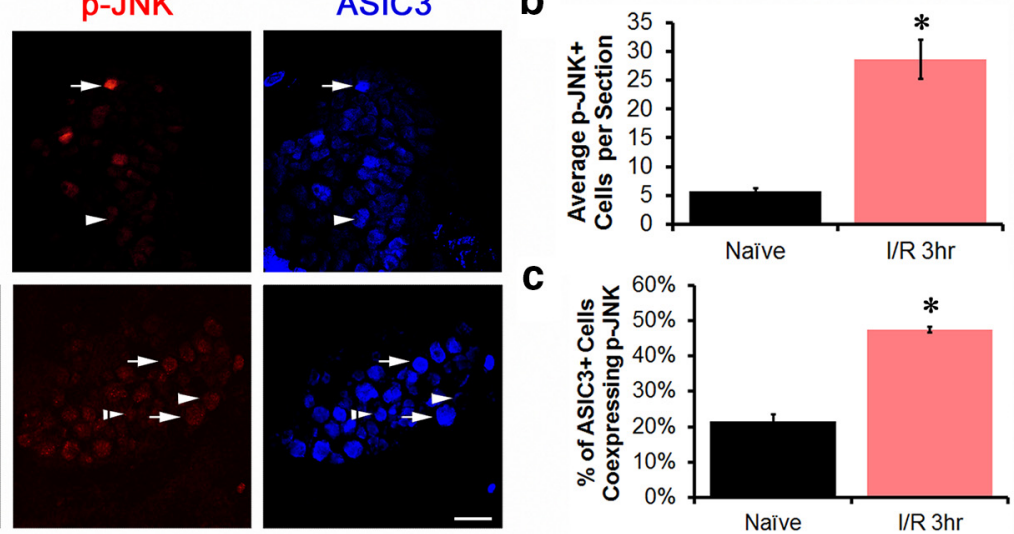

C
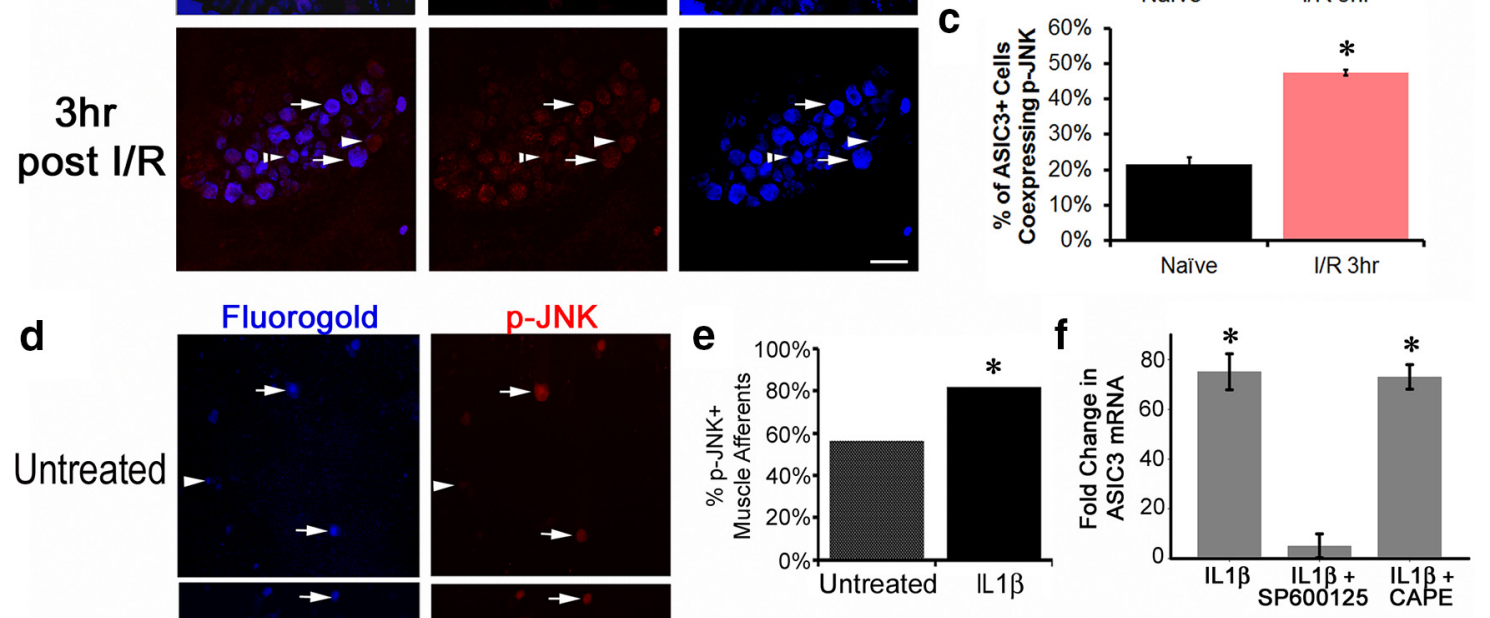

IL1 $\beta$
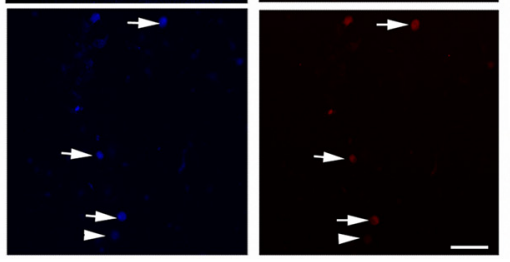

g

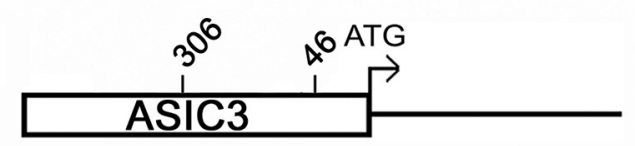

Figure 8. I/R induces ASIC3 expression through activation/phosphorylation of JNK. $\boldsymbol{a}$, Representative immunohistochemical staining of ASIC3 (blue) and p-JNK (red) protein in whole DRGs. Several p-JNK/ASIC3 double-labeled cells (arrows) were found in both conditions, as well as p-JNK single-labeled (arrowheads) and ASIC3 single-labeled (dashed arrowheads) cells. Shortly after I/R $(3 \mathrm{~h}$ ), DRG expression of $\mathrm{p}$-JNK significantly increases ( $\boldsymbol{b}$ ), as does $\mathrm{p}-\mathrm{JNK} / \mathrm{ASIC}$ coexpression (c) relative to naive conditions. $\boldsymbol{d}$, Representative immunohistochemical staining of $\mathrm{p}$-JNK (red) protein in primary afferents retrogradely labeled from the forepaw muscles with $\mathrm{FG}$ (blue, arrows) and cultured in untreated medium or medium enriched with IL $1 \beta$. IL $1 \beta$ treatment increases the numbers of p-JNK-positive cells in vitro (e) and increases the expression of ASIC3 mRNA ( $\boldsymbol{f})$ in individual muscle afferents. However, treatment of IL1 $\beta$-exposed cells with a JNK inhibitor (SP600125), but not an NF $\kappa$ B inhibitor (CAPE), completely prevents ASIC3 upregulation in single cells. $\boldsymbol{g}$, Schematic of AP1/Jun transcription factor binding sites on ASIC3 promoter region. Data are represented as mean \pm SEM and were analyzed via one-way ANOVA with Holm-Sidak test. ${ }^{*} p<0.05$ compared with other conditions. Scale bar, $60 \mu \mathrm{m}$.

et al., 2010), as well as in ocular afferents (Callejo et al., 2015). Recent studies analyzing meningeal afferents in an animal model of migraine linked inflammatory signaling in the periphery with ASIC-related afferent function, which mediated pain-related behaviors (Yan et al., 2012; Dussor, 2015). Here we show that group III/IV muscle afferent sensitization and phenotypic switching after I/R is dependent upon upregulation of either IL1r1 or ASIC3 (Figs. 2, 4, 6, 7), similar to these reports in other systems. However our data also suggest that this effect may be mediated by JNK activation in muscle afferents. Although it is likely that our observed effects are not mediated by NF $\kappa$ B signaling (Fig. 8), we cannot completely rule out other MAPK or SRC signaling pathways in this regulation. Regardless, our data imply that dynamic expression of pain-related proteins in peripheral nociceptors under conditions of altered blood flow and oxygenation (e.g., I/R) may be dependent upon unique target-derived inflammatory signaling mechanisms.

With our analyses of single DRG neurons, we were able to determine that, in naive animals, ASIC3 expression is constrained to the metabo-nociceptors and mechanically sensitive group III/IV muscle afferents, but $1 \mathrm{~d}$ after I/R, de novo ASIC3 expression was found in the DRGs and this appeared to be due to specific upregulation of this channel in metaboreceptors (Figs. 4, 5, Table 3). This correlates with previous reports of ASIC3 expression within both naive and injury-affected muscle afferents and the role of this channel in regulating mechanosensation and chemosensation (Sluka et al., 2003; Molliver et al., 2005; Benson and McCleskey, 2007; Fujii et al., 2008; Light et al., 2008; Birdsong et al., 2010; Yan et al., 2011). This de novo ASIC3 expression in metaboreceptors and mechanically sensitive muscle afferents was prevented in both of our siRNA knock-down conditions.

Despite robust behavioral effects, inhibition of IL1r1 or ASIC3 did not alter the I/R-induced increase in firing to the innocuous metabolite mixture (Figs. 2, 7), nor did it alter expression of P2X3 in DRGs or in functionally defined muscle afferents (Figs. 2, 3, 4, $5,6,7$, Table 2). Therefore, it is possible that another targetderived signaling molecule is responsible for upregulated P2X3 expression, which may drive changes in responsivity to "low" metabolites. This could be pursued in the future; however, our results clearly indicate that IL1r1 and ASIC3 are major contributors to I/R-induced alterations in muscle afferent function and pain-related behaviors because knock-down of these two receptors affected all of our behavioral measures, even while firing to innocuous metabolites remained elevated (Figs. 2, 7). Nevertheless, ASIC3-dependent phenotypic switching of metabolite-sensitive muscle afferents, rather than altered individual responsiveness to lactate, ATP, or protons, is a likely crucial mediator of pain-related behaviors after I/R because these afferents project directly to pain-specific lamina I and II 
(Jankowski et al., 2013) and, under conditions of I/R, would then be responding to a wider range of chemical stimulation.

Blood flow alterations simultaneously induce afferent sensitization and lead to inflammation, which could be further sensitizing already vulnerable afferents, altogether resulting in a persistent pain state (McMahon et al., 2015). This suggests that therapeutic interventions targeting the endogenous inflammatory reaction to ischemia/reperfusion injury (IL1 $\beta /$ IL $1 r 1$ ), rather than direct inhibition of channels that mediate altered mechanosensitivity and chemosensitivity (ASIC3), would be effective in subjects with I/R-based myalgia. Although this may seem counterintuitive due to the wound-healing aspect of the inflammatory response, this strategy could circumvent the initial afferent sensitization that develops into a persistent pain state found in ischemic myalgia.

\section{Multiple potential roles of muscle afferents after I/R}

Group III/IV muscle afferents are also not solely involved in nociception; they provide the peripheral sensory input for the exercise pressor reflex (EPR), a circuit that stimulates increased cardiac output and blood pressure during exercise (Zamir and Maixner, 1986; Kaufman and Hayes, 2002). Both ASIC3 and P2X3 have been linked to EPR regulation (Kaufman and Hayes, 2002; Hayes et al., 2008; McCord et al., 2010; Gerdle et al., 2014) and the combinatorial effects of ASIC3 and P2X3 in detecting metabolites during ischemia may be a major evoking stimulus for the EPR after injury (Stone et al., 2014). Here, P2X3 was found to be localized in small proportions to cells of all phenotypes, so it, like other P2X channels (Birdsong et al., 2010), may be aiding in detection of metabolites after $\mathrm{I} / \mathrm{R}$, but may play a larger role in EPR regulation than in nociception. Elucidating the mechanisms behind postinjury ASIC3 and P2X3 upregulation could lead to a number of therapeutic breakthroughs, not only in early myalgia interventions, but also in patients with comorbid alterations in EPR function as well. Nevertheless, our data suggest that the macrophage- and neutrophil-produced IL $1 \beta$ in the muscles during $\mathrm{I} / \mathrm{R}$ activates enhanced IL1r1 in muscle afferents (Fig. 1) to increase expression of ASIC3, possibly via JNK activation (Fig. 8), which modulates their mechanical thresholds and chemosensory function (Figs. 2, 3, 7) to direct pain-related behaviors after I/R (Figs. 1, 6).

\section{References}

Alam M, Smirk FH (1937) Observations in man upon a blood pressure raising reflex arising from the voluntary muscles. J Physiol 89:372-383. CrossRef Medline

Ali FN, Carman TL (2012) Medical management for chronic atherosclerotic peripheral arterial disease. Drugs 72:2073-2085. CrossRef Medline

Alvarez P, Green PG, Levine JD (2014) Role for monocyte chemoattractant protein-1 in the induction of chronic muscle pain in the rat. Pain 155: 1161-1167. CrossRef Medline

Benson CJ, McCleskey EW (2007) ASICs function as lactic acid sensors during cardiac ischemia. In: Molecular sensors for cardiovascular homeostasis (Wang DH, ed), pp 32-50. New York: Springer.

Benson CJ, Eckert SP, McCleskey EW (1999) Acid-evoked currents in cardiac sensory neurons: a possible mediator of myocardial ischemic sensation. Circ Res 84:921-928. CrossRef Medline

Birdsong WT, Fierro L, Williams FG, Spelta V, Naves LA, Knowles M, MarshHaffner J, Adelman JP, Almers W, Elde RP, McCleskey EW (2010) Sensing muscle ischemia: coincident detection of acid and ATP via interplay of two ion channels. Neuron 68:739-749. CrossRef Medline

Blaisdell FW (2002) The pathophysiology of skeletal muscle ischemia and the reperfusion syndrome: a review. Cardiovasc Surg 10:620-630. CrossRef Medline

Callejo G, Castellanos A, Castany M, Gual A, Luna C, Acosta MC, Gallar J,
Giblin JP, Gasull X (2015) Acid-sensing ion channels detect moderate acidifications to induce ocular pain. Pain 156:483-495. CrossRef Medline

Carmo-Araújo EM, Dal-Pai-Silva M, Dal-Pai V, Cecchini R, Anjos Ferreira AL (2007) Ischaemia and reperfusion effects on skeletal muscle tissue: morphological and histochemical studies. Int J Exp Pathol 88:147-154. CrossRef Medline

Chiechio S, Copani A, De Petris L, Morales ME, Nicoletti F, Gereau RW 4th (2006) Transcriptional regulation of metabotropic glutamate receptor $2 / 3$ expression by the NF-kappaB pathway in primary dorsal root ganglia neurons: a possible mechanism for the analgesic effect of L-acetylcarnitine. Mol Pain 2:20. CrossRef Medline

Christianson JA, Traub RJ, Davis BM (2006) Differences in spinal distribution and neurochemical phenotype of colonic afferents in mouse and rat. J Comp Neurol 494:246-259. CrossRef Medline

Coderre TJ, Xanthos DN, Francis L, Bennett GJ (2004) Chronic postischemia pain (CPIP): a novel animal model of complex regional pain syndrome-type I (CRPS-I; reflex sympathetic dystrophy) produced by prolonged hindpaw ischemia and reperfusion in the rat. Pain 112:94-105. CrossRef Medline

Davidson TJ, Harel S, Arboleda VA, Prunell GF, Shelanski ML, Greene LA, Troy CM (2004) Highly efficient small interfering RNA delivery to primary mammalian neurons induces MicroRNA-like effects before mRNA degradation. J Neurosci 24:10040-10046. CrossRef Medline

Dina OA, Green PG, Levine JD (2008) Role of interleukin-6 in chronic muscle hyperalgesic priming. Neuroscience 152:521-525. CrossRef Medline

Dussor G (2015) ASICs as therapeutic targets for migraine. Neuropharmacology 94:64-71. CrossRef Medline

Eisenhardt SU, Schmidt Y, Karaxha G, Iblher N, Penna V, Torio-Padron N, Stark GB, Bannasch H (2012) Monitoring molecular changes induced by ischemia/reperfusion in human free muscle flap tissue samples. Ann Plast Surg 68:202-208. CrossRef Medline

Ferreira SH, Lorenzetti BB, Bristow AF, Poole S (1988) Interleukin-1 beta as a potent hyperalgesic agent antagonized by a tripeptide analogue. Nature 334:698-700. CrossRef Medline

Fujii Y, Ozaki N, Taguchi T, Mizumura K, Furukawa K, Sugiura Y (2008) TRP channels and ASICs mediate mechanical hyperalgesia in models of inflammatory muscle pain and delayed onset muscle soreness. Pain 140: 292-304. CrossRef Medline

Gautam M, Benson CJ, Sluka KA (2010) Increased response of muscle sensory neurons to decreases in $\mathrm{pH}$ after muscle inflammation. Neuroscience 170:893-900. CrossRef Medline

Gerdle B, Ghafouri B, Ernberg M, Larsson B (2014) Chronic musculoskeletal pain: review of mechanisms and biochemical biomarkers as assessed by the microdialysis technique. J Pain Res 7:313-326. CrossRef Medline

Hallegua DS, Weisman MH (2002) Potential therapeutic uses of interleukin 1 receptor antagonists in human diseases. Ann Rheum Dis 61:960-967. CrossRef Medline

Hayes SG, McCord JL, Kaufman MP (2008) Role played by P2X and P2Y receptors in evoking the muscle chemoreflex. J Appl Physiol 104: 538-541. Medline

Immke DC, McCleskey EW (2001a) ASIC3: a lactic acid sensor for cardiac pain. ScientificWorldJournal 1:510-512. CrossRef Medline

Immke DC, McCleskey EW (2001b) Lactate enhances the acid-sensing $\mathrm{Na}+$ channel on ischemia-sensing neurons. Nat Neurosci 4:869-870. CrossRef Medline

Jankowski MP, Koerber HR (2010) Neurotrophic factors and nociceptor sensitization. In: Translational pain research: from mouse to man (Kruger L, Light AR, eds). Boca Raton, FL: CRC

Jankowski MP, Cornuet PK, McIlwrath S, Koerber HR, Albers KM (2006) SRY-box containing gene 11 (Sox11) transcription factor is required for neuron survival and neurite growth. Neuroscience 143:501-514. CrossRef Medline

Jankowski MP, Lawson JJ, McIlwrath SL, Rau KK, Anderson CE, Albers KM, Koerber HR (2009a) Sensitization of cutaneous nociceptors after nerve transection and regeneration: possible role of target-derived neurotrophic factor signaling. J Neurosci 29:1636-1647. CrossRef Medline

Jankowski MP, Mcllwrath SL, Jing X, Cornuet PK, Salerno KM, Koerber HR, Albers KM (2009b) Sox11 transcription factor modulates peripheral nerve regeneration in adult mice. Brain Res 1256:43-54. CrossRef Medline

Jankowski MP, Rau KK, Soneji DJ, Anderson CE, Koerber HR (2010) Enhanced artemin/GFRalpha3 levels regulate mechanically insensitive, 
heat-sensitive C-fiber recruitment after axotomy and regeneration. J Neurosci 30:16272-16283. CrossRef Medline

Jankowski MP, Rau KK, Soneji DJ, Ekmann KM, Anderson CE, Molliver DC, Koerber HR (2012a) Purinergic receptor P2Y1 regulates polymodal C-fiber thermal thresholds and sensory neuron phenotypic switching during peripheral inflammation. Pain 153:410-419. CrossRef Medline

Jankowski MP, Soneji DJ, Ekmann KM, Anderson CE, Koerber HR (2012b) Dynamic changes in heat transducing channel TRPV1 expression regulate mechanically insensitive, heat sensitive C-fiber recruitment after axotomy and regeneration. J Neurosci 32:17869-17873. CrossRef Medline

Jankowski MP, Rau KK, Ekmann KM, Anderson CE, Koerber HR (2013) Comprehensive phenotyping of group III and IV muscle afferents in mouse. J Neurophysiol 109:2374-2381. CrossRef Medline

Jankowski MP, Ross JL, Weber JD, Lee FB, Shank AT, Hudgins RC (2014) Age-dependent sensitization of cutaneous nociceptors during developmental inflammation. Mol Pain 10:34. CrossRef Medline

Katz DL, Greene L, Ali A, Faridi Z (2007) The pain of fibromyalgia syndrome is due to muscle hypoperfusion induced by regional vasomotor dysregulation. Med Hypotheses 69:517-525. CrossRef Medline

Kaufman MP, Hayes SG (2002) The exercise pressor reflex. Clin Auton Res 12:429-439. CrossRef Medline

Kurimoto K, Yabuta Y, Ohinata Y, Ono Y, Uno KD, Yamada RG, Ueda HR, Saitou M (2006) An improved single-cell cDNA amplification method for efficient high-density oligonucleotide microarray analysis. Nucleic Acids Res 34:e42. CrossRef Medline

Kurimoto K, Yabuta Y, Ohinata Y, Saitou M (2007) Global single-cell cDNA amplification to provide a template for representative high-density oligonucleotide microarray analysis. Nat Protoc 2:739-752. CrossRef Medline

Li J, Gao Z, Kehoe V, Xing J, King N, Sinoway L (2008) Interstitial adenosine triphosphate modulates muscle afferent nerve-mediated pressor reflex. Muscle Nerve 38:972-977. CrossRef Medline

Light AR, Hughen RW, Zhang J, Rainier J, Liu Z, Lee J (2008) Dorsal root ganglion neurons innervating skeletal muscle respond to physiological combinations of protons, ATP, and lactate mediated by ASIC, P2X, and TRPV1. J Neurophysiol 100:1184-1201. CrossRef Medline

Malin SA, Davis BM, Molliver DC (2007) Production of dissociated sensory neuron cultures and considerations for their use in studying neuronal function and plasticity. Nat Protocols 2:152-160. CrossRef Medline

Mamet J, Baron A, Lazdunski M, Voilley N (2002) Proinflammatory mediators, stimulators of sensory neuron excitability via the expression of acid-sensing ion channels. J Neurosci 22:10662-10670. Medline

McCord JL, Tsuchimochi H, Kaufman MP (2010) P2X2/3 and P2X3 receptors contribute to the metaboreceptor component of the exercise pressor reflex. J Appl Physiol (1985) 109:1416-1423.

McMahon SB, La Russa F, Bennett DL (2015) Crosstalk between the nociceptive and immune systems in host defence and disease. Nat Rev Neurosci 16:389-402. CrossRef Medline

Mense S (2003) The pathogenesis of muscle pain. Curr Pain Headache Rep 7:419-425. CrossRef Medline

Mense S (2008) Muscle pain: mechanisms and clinical significance. Dtsch Arztebl Int 105:214-219. CrossRef Medline

Molliver DC, Immke DC, Fierro L, Paré M, Rice FL, McCleskey EW (2005) ASIC3, an acid-sensing ion channel, is expressed in metaboreceptive sensory neurons. Mol Pain 1:35. CrossRef Medline

Naves LA, McCleskey EW (2005) An acid-sensing ion channel that detects ischemic pain. Braz J Med Biol Res 38:1561-1569. Medline

Noma N, Shinoda M, Honda K, Kiyomoto M, Dezawa K, Nakaya Y, Komiyama O, Imamura Y, Iwata K (2013) Interaction of IL-1beta and P2X(3) receptor in pathologic masseter muscle pain. J Dent Res 92:456460. CrossRef Medline

O’Neill LA, Greene C (1998) Signal transduction pathways activated by the IL-1 receptor family: ancient signaling machinery in mammals, insects, and plants. J Leukoc Biol 63:650-657. Medline
Pollak KA, Swenson JD, Vanhaitsma TA, Hughen RW, Jo D, White AT, Light KC, Schweinhardt P, Amann M, Light AR (2014) Exogenously applied muscle metabolites synergistically evoke sensations of muscle fatigue and pain in human subjects. Exp Physiol 99:368-380. CrossRef Medline

Queme LF, Ross JL, Lu P, Hudgins RC, Jankowski MP (2016) Dual modulation of nociception and cardiovascular reflexes during peripheral ischemia through P2Y1 receptor-dependent sensitization of muscle afferents. J Neurosci 36:19-30. CrossRef Medline

Ross JL, Queme LF, Shank AT, Hudgins RC, Jankowski MP (2014) Sensitization of group III and IV muscle afferents in the mouse after ischemia and reperfusion injury. J Pain 15:1257-1270. CrossRef Medline

Seo HS, Roh DH, Yoon SY, Kang SY, Moon JY, Kim HW, Han HJ, Chung JM, Beitz AJ, Lee JH (2010) Peripheral acid-sensing ion channels and P2X receptors contribute to mechanical allodynia in a rodent thrombusinduced ischemic pain model. J Pain 11:718-727. CrossRef Medline

Sinoway L, Prophet S, Gorman I, Mosher T, Shenberger J, Dolecki M, Briggs $\mathrm{R}$, Zelis R (1989) Muscle acidosis during static exercise is associated with calf vasoconstriction. J Appl Physiol 66:429-436. Medline

Sluka KA, Price MP, Breese NM, Stucky CL, Wemmie JA, Welsh MJ (2003) Chronic hyperalgesia induced by repeated acid injections in muscle is abolished by the loss of ASIC3, but not ASIC1. Pain 106:229-239. CrossRef Medline

Sluka KA, Radhakrishnan R, Benson CJ, Eshcol JO, Price MP, Babinski K, Audette KM, Yeomans DC, Wilson SP (2007) ASIC3 in muscle mediates mechanical, but not heat, hyperalgesia associated with muscle inflammation. Pain 129:102-112. CrossRef Medline

Stone AJ, Yamauchi K, Kaufman MP (2014) Purinergic 2X receptors play a role in evoking the exercise pressor reflex in rats with peripheral artery insufficiency. Am J Physiol Heart Circ Physiol 306:H396-H404. CrossRef Medline

Tsujino H, Kondo E, Fukuoka T, Dai Y, Tokunaga A, Miki K, Yonenobu K, Ochi T, Noguchi K (2000) Activating transcription factor 3 (ATF3) induction by axotomy in sensory and motoneurons: A novel neuronal marker of nerve injury. Mol Cell Neurosci 15:170-182. CrossRef Medline

Vigers GP, Anderson LJ, Caffes P, Brandhuber BJ (1997) Crystal structure of the type-I interleukin-1 receptor complexed with interleukin-1beta. Nature 386:190-194. CrossRef Medline

Walder RY, Rasmussen LA, Rainier JD, Light AR, Wemmie JA, Sluka KA (2010) ASIC1 and ASIC3 play different roles in the development of hyperalgesia after inflammatory muscle injury. J Pain 11:210-218. CrossRef Medline

Wasner G, Schattschneider J, Heckmann K, Maier C, Baron R (2001) Vascular abnormalities in reflex sympathetic dystrophy (CRPS I): mechanisms and disgnostic value. Brain 124:587-599. CrossRef Medline

Xu J, Brennan TJ (2010) Guarding pain and spontaneous activity of nociceptors after skin versus skin plus deep tissue incision. Anesthesiology 112: 153-164. CrossRef Medline

Yagi J, Wenk HN, Naves LA, McCleskey EW (2006) Sustained currents through ASIC3 ion channels at the modest $\mathrm{pH}$ changes that occur during myocardial ischemia. Circ Res 99:501-509. CrossRef Medline

Yan J, Edelmayer RM, Wei X, De Felice M, Porreca F, Dussor G (2011) Dural afferents express acid-sensing ion channels: a role for decreased meningeal $\mathrm{pH}$ in migraine headache. Pain 152:106-113. CrossRef Medline

Yan J, Melemedjian OK, Price TJ, Dussor G (2012) Sensitization of dural afferents underlies migraine-related behavior following meningeal application of interleukin-6 (IL-6). Mol Pain 8:6. CrossRef Medline

Zamir N, MaixnerW (1986) The relationship between cardiovascular and pain regulatory systems. Ann N Y Acad Sci 467:371-384. CrossRef Medline

Zempsky WT, Palermo TM, Corsi JM, Lewandowski AS, Zhou C, Casella JF (2013) Daily changes in pain, mood and physical function in children hospitalized for sickle cell disease pain. Pain Res Manag 18:33-38. CrossRef Medline 